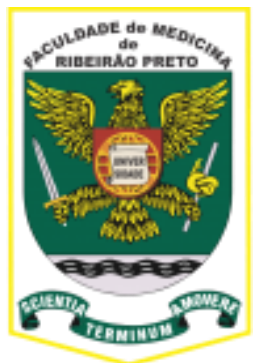

UNIVERSIDADE DE SÃO PAULO

FACULDADE DE MEDICINA DE RIBEIRÃO PRETO

PROGRAMA DE PÓS-GRADUAÇÃO EM FARMACOLOGIA

JOSÉ TELES DE OLIVEIRA NETO

ESTUDO DOS EFEITOS VASCULARES DA INFECÇÃO INDUZIDA PELO ARBOVÍRUS CHIKUNGUNYẢ 


\section{ESTUDO DOS EFEITOS VASCULARES DA INFECÇÃO INDUZIDA PELO ARBOVÍRUS CHIKUNGUNYA}

Versão corrigida. A versão original encontra-se disponível tanto na Biblioteca da Unidade que aloja o Programa, quanto na Biblioteca Digital de Teses e Dissertações da USP (BDTD)

Dissertação de Mestrado apresentada à Faculdade de Medicina de Ribeirão Preto da Universidade de São Paulo para obtenção do título de Mestre em Ciências.

Área de concentração: Farmacologia

Orientadora: Profa. Dra. Rita de Cássia Aleixo Tostes Passaglia

Coorientadora: Dra. Emiliana Pereira Abrão 
Autorizo a reprodução e divulgação total ou parcial deste trabalho, por qualquer meio convencional ou eletrônico, para fins de estudo e pesquisa, desde que citada a fonte.

Departamento Técnico do Sistema Integrado de Bibliotecas da USP Universidade de São Paulo

Ficha Catalográfica

Oliveira Neto, José Teles.

Estudo dos efeitos vasculares da infecção induzida pelo arbovírus Chikungunya. Ribeirão Preto, 2021.72 p., $30 \mathrm{~cm}$.

Dissertação de Mestrado, apresentada à Faculdade de Medicina de Ribeirão Preto/Universidade de São Paulo - Área de concentração: Farmacologia.

Orientadora: Tostes, Rita de Cássia

1. Chikungunya. 2. Espécies Reativas de Oxigênio. 3. Óxido Nítrico Sintase. 4. Disfunção vascular. 


\section{FOLHA DE APROVAÇÃO}

Autor: José Teles de Oliveira Neto

Título: Estudo dos efeitos vasculares da infecção induzida pelo arbovírus Chikungunya.

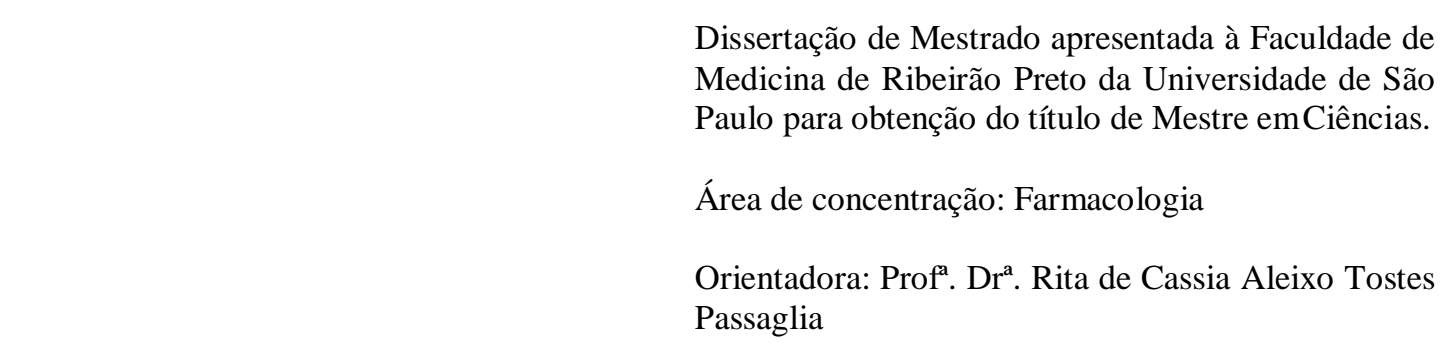

Aprovado em:

1

I

\section{Banca Examinadora}

$\begin{array}{ll}\text { Presidente: } & \text { Assinatura: } \\ & \text { Nome: } \\ & \text { Instituição: } \\ & \\ \text { Examinador(a): } & \text { Assinatura: } \\ & \text { Nome: } \\ & \text { Instituição: } \\ & \\ \text { Examinador(a): } & \text { Assinatura: } \\ & \text { Nome: } \\ & \text { Instituição: }\end{array}$




\section{Dedicatória}

Aos meus pais,

Josielma Ferreira e Jorge Oliveira

A estes que se doaram inteiros e muitas vezes renunciaram às suas vontades para que pudessem realizar as minhas, agradeço pelo amor, carinho, amparo, dedicação e torcida pelas conquistas, pelo conforto e segurança de uma família sem igual. Obrigado por tudo! 


\section{Agradecimentos}

À Deus acima de todas as coisas. Pela vida e bênçãos alcançadas durante toda a jornada.

À toda minha família, em especial aos meus pais, Josielma e Jorge, que nunca mediram esforços para a realização de todos os meus sonhos, além do incentivo, amor incondicional, me encorajando a lutar pelos meus objetivos, a superar desafios, compreendendo os momentos de ausência e pela valorização de cada conquista. Aos meus irmãos, Jéssyka e Thyago, pelo carinho e fraternidade. Ao meu sobrinho João Henrique por ser minha inspiração e estímulo em busca do meu melhor. É fundamental ter uma família unida, afetuosa na qual posso confiar em todos os momentos.

Ao meu avô José Teles de Oliveira, muito obrigado por sempre estar presente e por todos os esforços empenhados na minha educação e formação como cidadão. Serei eternamente grato pelos ensinamentos e exemplo de homem íntegro e honesto que o senhor construiu.

À minha querida tia Joelma Silva de Oliveira (in memoriam), muito obrigado pelo seu carinho e apoio durante o tempo que passamos juntos. Lembrarei com ternura dos seus conselhos, palavras de incentivo e do seu modo único e alegre que nos faz tanta falta. Guardarei com muito afeto o seu sorriso e abraços.

Ao Raphael Henrique, obrigado pelo companheirismo, cumplicidade, amor, carinho e incentivo em todos os momentos.

Aos meus pets, Mafalda, Otto e Calvin, obrigado pela companhia, amor e carinho incondicionais.

Aos meus melhores amigos: André Oliveira, Bruna Mazullo, Beatriz Sales, Daianny Ornilio, Daniel Rodrigues, Elizabete Medeiros, Fernanda Aquino, Flávia Aguiar, Leony Kevin, Rayanna Soares, Thaysa Souto e Vitória Almeida. É um privilégio ter pessoas tão especiais ao meu lado. Não tenho palavras suficientes para agradecer o apoio que vocês me ofereceram nos momentos em que tanto precisei. Agradeço imensamente pelo companheirismo e pela amizade que me fizeram crescer e superar cada desafio. 
À Profa. Dra. Rita de Cássia Aleixo Tostes Passaglia, obrigado pela oportunidade, orientação, dedicação, compromisso, incentivo e confiança em mim depositados. Além de ser um exemplo de mulher e cientista que inspira a todos.

À Dra. Emiliana Pereira Abrão, obrigado pela confiança e suporte científico que foram fundamentais para a continuidade e desenvolvimento desse trabalho.

À Dra. Josiane Fernandes da Silva, obrigado pela amizade, paciência, generosidade, humildade, colaboração e auxílio nos experimentos.

Ao Prof. Dr. Eurico de Arruda Neto (Laboratório de Pesquisa em Patogênese Viral do Centro de Pesquisa em Virologia da FMRP-USP), obrigado pelo suporte científico e pelas contribuições valiosas para o aprimoramento do trabalho.

Ao Juliano de Paula Souza, obrigado pelo suporte científico, acolhimento e auxílio nos experimentos. Além de sua amizade e solicitude. Você foi essencial para o desenvolvimento deste trabalho. Também agradeço aos demais alunos do Laboratório de Pesquisa em Patogênese Viral do Centro de Pesquisa em Virologia da FMRP-USP.

Ao suporte técnico dos laboratórios de Farmacologia Cardiovascular. Obrigado, Carla Pavan e Giuliana Bertozi, por auxiliarem e facilitarem o trabalho desenvolvido nos laboratórios do nosso grupo de pesquisa.

À banca examinadora pelas considerações e sugestões que contribuíram para o enriquecimento deste trabalho.

Aos amigos de laboratório: Alecsander Bressan, Aline Fedoce, Allan Carvalho, Daniel Rodrigues, Diane Rassi, Diego, Fernanda Minelli, Jeimison Santos, Josiane Silva, Juliano Vilela, Juliana Bolsoni, Júlio Neto, Mirele Rezende, Paula Barros, Pedro, Rafael Fais, Rafael Menezes, Sara Hott, Simone Potje e Tiago Januário pelas colaborações, pelos ensinamentos e convívio agradável, por compartilharem conhecimentos e experiências, contribuindo para o meu amadurecimento profissional e pessoal. 
Aos funcionários administrativos do Departamento de Farmacologia da FMRP-USP, em especial a Gislaine e Ramon pela atenção e compromisso.

À Universidade de São Paulo, à Faculdade de Medicina de Ribeirão Preto e ao Centro de Pesquisas em Doenças Inflamatórias (CRID), por me concederem a estrutura necessária para a realização desse trabalho.

Às agências de fomento CNPq, FAPESP e CAPES pelo apoio financeiro fornecido para o desenvolvimento desse trabalho.

A todos que direta ou indiretamente contribuíram durante essa jornada, sou grato. 
"É que tem mais chão nos meus olhos do que cansaço nas minhas pernas, mais esperança nos meus passos do que tristeza nos meus ombros, mais estrada no meu coração do que medo na minha cabeça."

Cora Coralina 
Resumo 


\section{OLIVEIRA NETO, JT. Estudo dos efeitos vasculares da infecção induzida pelo arbovírus}

Chikungunya. 2021. 72 p. Dissertação (Mestrado em Farmacologia) - Faculdade de Medicina de Ribeirão Preto, Universidade de São Paulo, Ribeirão Preto, 2021.

$\mathrm{O}$ vírus Chikungunya (CHIKV) é um arbovírus reemergente, cuja infecção causa doença febril associada a fortes dores nas articulações, mialgia e comprometimento cardiovascular. Embora a resposta imune ao CHIKV seja bem descrita, demonstrando a participação de diversas células do sistema imune, um melhor entendimento dos mecanismos de interação vírus-hospedeiro que afetam o sistema vascular pode levar a intervenções terapêuticas mais eficazes. Há evidências que a Chikungunya está associada a sintomas de bradicardia e hipotensão, além de outros efeitos cardiovasculares, incluindo a geração de espécies reativas de oxigênio (EROs) e produção de citocinas pró e anti-inflamatórias. Considerando que a resposta inflamatória e o equilíbrio redox são capazes de interferir na homeostase vascular, foi testada a hipótese que a infecção por CHIKV compromete a função arterial por ações diretas em células vasculares e por mecanismos que envolvem estresse oxidativo. Foram utilizados camundongos C57BL/6J, machos, com seis semanas. Os camundongos foram divididos em dois grupos experimentais: 1) infectados com CHIKV e 2) Mock-veículo. Os camundongos foram infundidos com CHIKV (1,0 x $\left.10^{6} \mathrm{PFU}\right)$ ou meio de cultura pela via intracaudal. A função vascular foi avaliada em anéis de aorta torácica usando um miógrafo para registrar a tensão isométrica. Células endoteliais (EA.hy926) foram infectadas com CHIKV (MOI 1.0). A produção de ROS foi avaliada por quimiluminescência com lucigenina e a expressão de proteínas, por western blot. Diferenças significativamente estatísticas foram consideradas quando $\mathrm{p}<0,05$. Todos os procedimentos foram aprovados pela Comissão de Ética no Uso de Animais (CEUA) da Faculdade de Medicina de Ribeirão Preto (171/2019). Os camundongos infectados apresentaram menor resposta vasoconstritora a FEN 48 horas (h) após a infecção (Rmax CHIKV = 126,8 \pm 4,34*; Rmax Mock = 178,8 \pm 5,04), que foi restaurada peloinibidor de NOS (L-NAME $300 \mu \mathrm{M})(\mathrm{Rmax}$ CHIKV = 219,7 \pm 10,66; Rmax Mock $=214,4 \pm 6,81)$ e remoção do endotélio. Não houve diferença na resposta vasodilatadora à $\mathrm{ACh}(\mathrm{Rmax} \mathrm{CHIKV}=88,22 \pm 2,85 ; \mathrm{Rmax}$ Mock = 85,37 $\pm 1,78)$. Aortas de camundongos infectados com CHIKV apresentaram aumento da geração de ROS [Lucigenina (RLU) - Basal: 88,6 \pm 4,7; CHIKV: 163,7 \pm 17,0]. A infecção por CHIKV aumentou a expressão proteica de

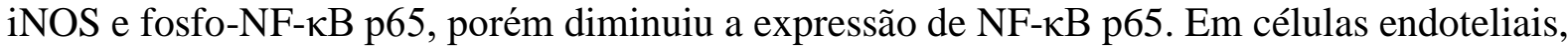
o CHIKV induziu a produção de EROs e aumentou a expressão da proteína endotelial ICAM1, relacionada a processos de ativação endotelial. Estes dados sugerem que o aumento da produção de EROs e expressão da iNOS, desencadeado pela ação direta do CHIKV em células vasculares, altera a sinalização de NO, promovendo ativação de células endoteliais e processos inflamatórios, com consequente disfunção vascular. Sendo assim, esse estudo fornece novas evidências para o envolvimento de disfunção vascular associada alterações nas vias ROS/NFkB/iNOS/NO na patogênese de Chikungunya.

Palavras-chave: Chikungunya. Espécies Reativas do Oxigênio. Óxido Nítrico Sintase.

Disfunção Vascular. 
Abstract

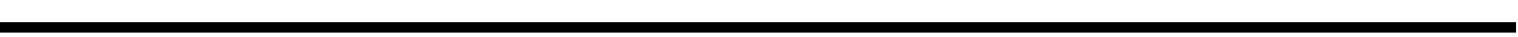




\section{OLIVEIRA NETO, JT. Vascular effects of the infection by the Chikungunya arbovirus.}

2021. 72 p. Dissertation (Master of Sciences - Pharmacology) - Ribeirao Preto Medical School, University of Sao Paulo, Ribeirao Preto, 2021.

The Chikungunya virus (CHIKV) is a reemerging arbovirus, whose infection causes febrile illness associated with severe joint pain, myalgia and cardiovascular impairment. Although the immune response to CHIKV is well described, demonstrating the participation of several cells of the immune system, a better understanding of the mechanisms of virus-host interaction that affect the vascular system can lead to more effective therapeutic interventions. There is evidence that Chikungunya is associated with symptoms of bradycardia and hypotension, in addition to other cardiovascular effects, including the generation of reactive oxygen species (ROSs) and production of pro and anti-inflammatory cytokines. Considering that the inflammatory response and redox balance are capable of interfering with vascular homeostasis, the hypothesis that CHIKV infection compromises arterial function by direct actions on vascular cells and by mechanisms involving oxidative stress was tested. Male C57BL/6J mice, six weeks old, were used. The mice were divided into two experimental groups: 1) infected with CHIKV and 2) Mock-vehicle. The mice were infused with CHIKV (1.0 x 106 PFU) or culture medium via the intracaudal route. Vascular function was assessed in thoracic aortic rings using a myograph to record isometric tension. Endothelial cells (EA.hy926) were infected with CHIKV (MOI 1.0). The production of ROS was evaluated by chemiluminescence with lucigenin and the expression of proteins by western blot. Significantly statistical differences were considered when $\mathrm{p}<0.05$. All procedures were approved by the Ethics Committee on the Use of Animals (CEUA) of the Ribeirão Preto Medical School (171/2019). Infected mice showed less vasoconstrictor response to FEN 48 hours (h) after infection $(\mathrm{Rmax} \mathrm{CHIKV}=126.8 \pm 4.34 *$; Rmax Mock $=178.8 \pm 5.04)$, which was restored by the NOS inhibitor ( L-NAME $300300 \mu \mathrm{M})(\mathrm{Rmax}$ CHIKV = 219.7 \pm 10.66 ; Rmax Mock $=214.4 \pm 6.81)$ and removal of the endothelium. There was no difference in the vasodilator response to $\mathrm{ACh}(\mathrm{Rmax} \mathrm{CHIKV}=88.22 \pm 2.85)$; $\mathrm{Rmax}$ Mock $=85.37 \pm 1.78)$. Aortas of mice infected with CHIKV showed increased ROS generation [Lucigenin (RLU) - Basal: 88.6 \pm 4.7; CHIKV: $163.7 \pm 17.0]$. CHIKV infection increased the protein expression of iNOS and

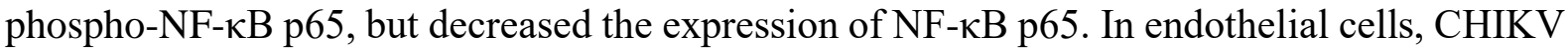
induced the production of ROS and increased the expression of the endothelial protein ICAM1 , related to endothelial activation processes. These data suggest that the increase in ROS production and iNOS expression, triggered by the direct action of CHIKV in vascular cells, alters NO signaling, promoting activation of endothelial cells and inflammatory processes, with consequent vascular dysfunction. Therefore, this study provides new evidence for the involvement of vascular dysfunction linked to alterations in ROS/NF-kB/iNOS/NO pathways in the pathogenesis of Chikungunya.

Keywords: Chikungunya. Reactive Oxygen Species. Nitric Oxide Synthase. Vascular dysfunction. 
Lista de abreviaturas, siglas e símbolos 
micrograma

$\mu \mathrm{L}$

microlitro

$\mu \mathrm{m}$

micrômetro

$\mathrm{ACh}$

acetilcolina

ANGII

angiotensina II

BSA

albumina bovino sérica (bovine serum albumin)

$\mathrm{C}$

célsius

$\mathrm{Ca}^{2+}$

cálcio

$\mathrm{CaCl}_{2}$

cloreto de cálcio

$\mathrm{CO}_{2}$

dióxido de carbono

CEUA

Comissão de Ética no Uso de Animais da FMRP

CONCEA

Conselho Nacional de Experimentação Animal

DNA

ácido desoxirribonucleico

E

$\mathrm{EC}_{50}$

EPM

EROs

etídio

concentração efetiva do agonista que produz $50 \%$ do efeito máximo

erro padrão da média

espécies reativas de oxigênio

FEN

fenilefrina

h

horas

IL-6

interleucina-6

iNOS

óxido nítrico sintase induzível

$\mathrm{K}^{+}$

potássio

$\mathrm{KCl}$

cloreto de potássio

$\mathrm{kg}$

quilogramas

$\mathrm{KH}_{2} \mathrm{PO}_{4}$

fosfato monopotássico

M

molar

$\mathrm{mg}$

miligramas

$\mathrm{MgSO}_{4}$

sulfato de magnésio

$\min$

minuto 
$\mathrm{ml}$

$\mathrm{mm}$

$\mathrm{mM}$

$\mathrm{mN}$

MOI

PFU

$\mathrm{NaCl}$

NADPH

$\mathrm{NaHCO}_{3}$

NO

$\mathrm{NF}-\kappa \mathrm{B}$

$\mathrm{O}_{2}{ }^{-}$

$\mathrm{O}_{2}$

PBS

$\mathrm{pD}_{2}$

rpm

SDS

SFB

TBARS

TNF- $\alpha$

V

VCAM-1

WT mililitro

milímetro

milimolar

milinewton

multiplicidade de infecção (multiplicity of infection)

unidade formadora de placa (plaque-forming unit)

cloreto de sódio

fosfato de dinucleótido de nicotinamida e adenina

bicarbonato de sódio

óxido nítrico (nitric oxide)

fator de transcrição nuclear kappa B (nuclear fator kappa B)

ânion superóxido

oxigênio

tampão fosfato salino (phosphate buffer saline)

logaritmo negativo da concentração efetiva do agonista que produz $50 \%$ do efeito máximo

rotação por minuto

dodecil sulfato de sódio (sodium dodecyl sulfate)

soro fetal bovino

substâncias reativas ao ácido tiobarbitúrico (thiobarbituric acid reactive substances)

fator de necrose tumoral alfa (tumor necrosis fator-alpha)

volt

molécula de adesão celular vascular-1 (vascular cell adhesion molecule)

camundongo tipo selvagem (wild type) 
Lista de figuras 
Figura 1 - Esquema representativo da hipótese.

Figura 2 - Curvas concentração-efeito cumulativas à fenilefrina (FEN) em aortas com endotélio de camundongos infectados (CHIKV) ou infundidos com veículo (Mock). 48

Figura 3 - A infecção por CHIKV aumento a geração de ânion superóxido em aorta. 49

Figura 4 - A infecção por CHIKV diminui a geração de peróxido de hidrogênio em aorta. 50

Figura 5 - A infecção com CHIKV aumenta os níveis de nitrato. 50

Figura 6 - Curvas concentração-efeito cumulativas à fenilefrina (FEN) em anéis de aorta com e sem endotélio. 51

Figura 7 - Curvas concentração-efeito cumulativas à FEN na presença de inibidores específicos (Tiron e L-NAME) em aortas torácicas de camundongos C57BL/6J infectados com CHIKV 52

Figura 8 - Animais infectados por CHIKV apresentam diminuição da pressão arterial sistólica 48 horas pós- infecção

Figura 9 - A infecção com CHIKV aumenta a expressão de componentes que indicam ativação da via do $\mathrm{NF}-\kappa \mathrm{B}$.

Figura 10 - A infecção por CHIKV aumenta ânion superóxido e marcadores de estresse oxidativo em células endoteliais EA.hy926..... 55

Figura 11 - A infecção por CHIKV aumenta componentes que indicam ativação da via do NF-Kb em células endoteliais (AE.hy926). 
Lista de tabelas 
Tabela 1 - Anticorpos utilizados nos ensaios de Western blotting..... .41

Tabela 2 - Valores de $\mathrm{p} D_{2}$ para fenilefrina e acetilcolina em aortas torácicas provenientes de camundongos C57BL/6J wild type infectados com CHIKV e/ou veículo. 49

Tabela 3 - Valores de $\mathrm{p} D_{2}$ para fenilefrina e acetilcolina em aortas torácicas provenientes de camundongos $\mathrm{C} 57 \mathrm{BL} / 6 \mathrm{~J}$ wild type infectados por $\mathrm{CHIKV}$, em presença de inibidores ou veículo. 52 
Sumário 


\section{SUMÁRIO}

1 INTRODUÇÃO ..............................................................................................26

1.1 ARBOVÍRUS E O SISTEMA CARDIOVASCULAR ............................................26

1.2 PROCESSO INFLAMATÓRIO E ESTRESSE OXIDATIVO NA INFECÇÃO VIRAL

(1)

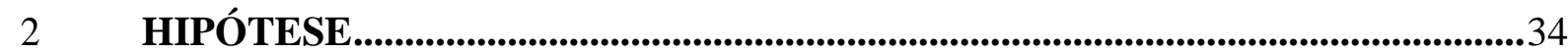

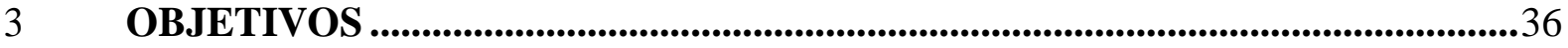

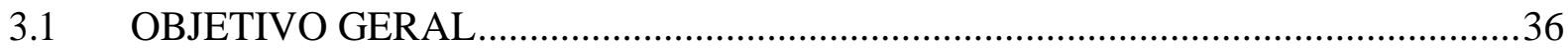

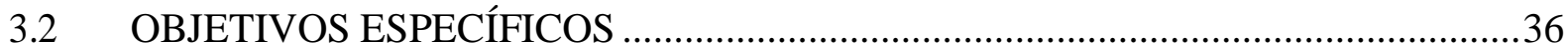

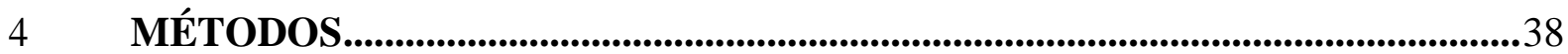

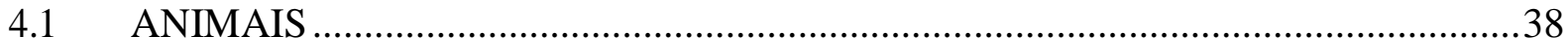

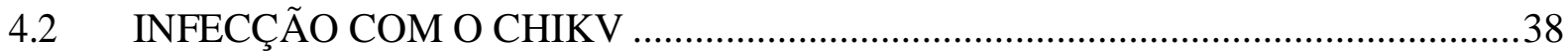

4.3 ESTUDO DA REATIVIDADE VASCULAR EM ANÉIS DE AORTA ISOLADO..38

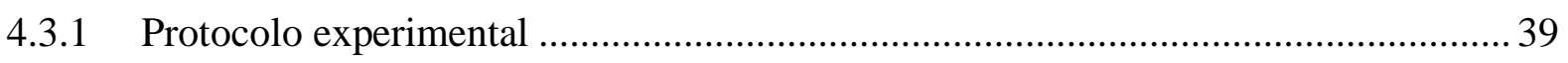

ENSAIOS IN VITRO

4.4.1 Cultura de células endoteliais (EA.hy926) e infecção viral.......................................39

4.4.2 Análise de expressão proteica por Western blotting ...................................................40

4.5 QUANTIFICAÇÃO DE CITOCINAS POR ELISA …............................................

4.6 ESTUDO DA GERAÇÃO DE ESPÉCIES REATIVAS DE OXIGÊNIO..................42

4.6.1 Medida da produção de ânion superóxido $\left(\mathrm{O}_{2}^{-}\right)$por Lucigenina ...........42

4.6.2 Medida da produção de peróxido de hidrogênio $\left(\mathrm{H}_{2} \mathrm{O}_{2}\right)$ por Amplex Red...................42

4.6.3 Avaliação de níveis de marcadores de estresse oxidativo - TBARS............................42

4.6.4 Medida da produção de nitrito $\left(\mathrm{NO}_{2}{ }^{-}\right)$pelo ensaio de Griess ....................................43

4.7 MEDIDA DA PRESSÃO ARTERIAL EM MODELO EXPERIMENTAL DE INFECÇÃO POR CHIKVPOR PLETISMOGRAFIA DE CAUDA ........................... 43

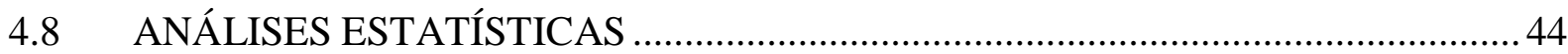


5.1 PADRONIZAÇÃO DO MODELO ANIMAL DE INFECÇÃO POR CHIKV

5.1.1 Efeitos da infecção com CHIKV sobre as respostas contrátil à fenilefrina e dilatadora à acetilcolina em aortas torácicas de camundongos .46

5.2 AVALIAÇÃO DA GERAÇÃO DE ÂNION SUPERÓXIDO $\left(\mathrm{O}_{2}{ }^{\bullet}\right)$ 49

5.3 AVALIAÇÃO DA GERAÇÃO DE PERÓXIDO DE HIDROGÊNIO $\left(\mathrm{H}_{2} \mathrm{O}_{2}\right)$ 49

5.4 AVALIAÇÃO DA PRODUÇÃO DE NITRITO $\left(\mathrm{NO}_{2}^{-}\right)$ .50

5.5 AVALIAÇÃO DO PAPEL DO ENDOTÉLIO NA REATIVIDADE VASCULAR EM CAMUNDONGOS INFECTADOS COM CHIKV .50

5.6 CURVAS CONCENTRAÇÃO-EFEITO CUMULATIVAS À FEN NA PRESENÇA DE L-NAME E TIRON

5.7 MEDIDA DA PRESSÃO ARTERIAL EM MODELO EXPERIMENTAL DE

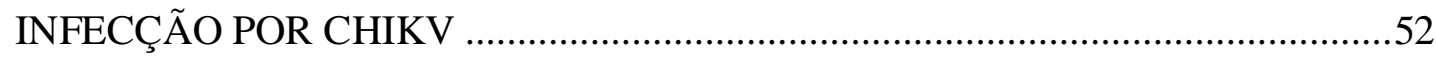

5.8 CURVAS CONCENTRAÇÃO-EFEITO CUMULATIVAS À FE NA PRESENÇA DE INIBIDORES ESPECÍFICOS (L-NAME E TIRON) ...................................... 53

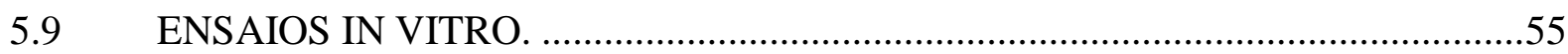

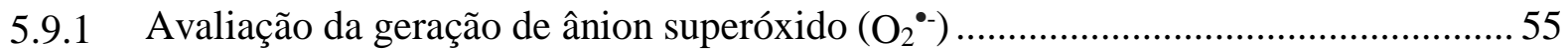

5.9.2 Avaliação dos componentes da via NF-kB em células endoteliais humanas (EA.hy926) 56

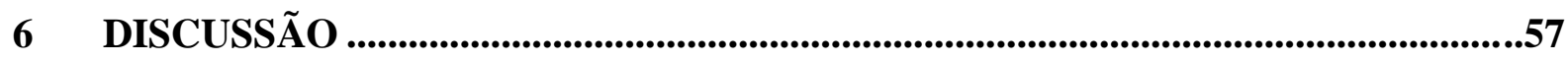

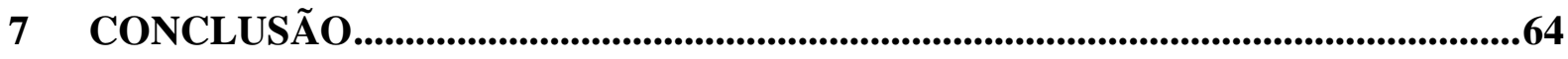

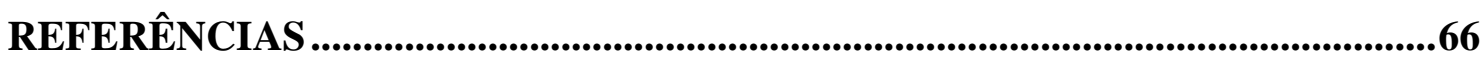

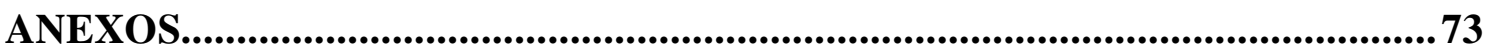




\section{INTRODUÇÃ̃O}

\subsection{ARBOVÍRUS E O SISTEMA CARDIOVASCULAR}

Os arbovírus (do inglês, arthropod-born vírus) compreendem um abrangente grupo de vírus que se utilizam de artrópodes hematófagos (e.g. mosquitos) para completarem o seu ciclo de vida (MUSSO \& GUBLER, 2016). Aqueles de importância médica humana pertencem a três famílias: Togaviridae (gênero Alphavirus), Flaviviridae (gênero Flavivírus) e Bunyaviridae (gêneros Bunyavirus, Orthobunyavirus, Nairovirus e Phlebovirus) (YOUNG et al., 2014). O gênero dos Flavivírus inclui as viroses de maior relevância médica e também epidemiológica, como o vírus dengue (DENV), o vírus da febre amarela (VFA) e o vírus Zika (ZIKV); o gênero Alphavirus inclui o vírus Chikungunya (CHIKV), todos eles transmitidos por vetores do gênero Aedes (YOUNG et al., 2014).

Atualmente estamos presenciando uma dramática emergência/reemergência de diferentes arboviroses (MAYER et al., 2017; YOUNG et al., 2017). Além das epidemias anuais causadas pelo vírus dengue (DENV) nos anos 2015 e 2016, ocorreram severas epidemias do vírus Zika na América do Sul em 2013 e 2014 e uma epidemia de Chikungunya se espalhou rapidamente pelo Caribe e América do Sul, impondo novos desafios aos gestores da saúde pública e, ao mesmo tempo, abrindo novos desafios de investigação e um vasto horizonte para pesquisas multidisciplinares e inovadoras (FISCHER \& STAPLES, 2014; KUCHARSKI et al., 2017).

Essas arboviroses apresentam um amplo espectro de manifestações clínicas. A dengue, em suas formas mais brandas, é caracterizada por febre alta, dores articulares e musculares, náusea, vômito e rash cutâneo, podendo evoluir para formas mais graves da doença como a síndrome do choque da dengue (DSS) e dengue hemorrágica, com falência múltipla de órgãos culminando em choque e morte (OLIVEIRA at. al., 2018). A infecção por CHIKV também leva a estados febris como parte de sua evolução clínica e sua forma grave é caracterizada pelo desenvolvimento de artralgia que pode persistir por vários anos. Outros relatos descrevem envolvimentos neurológicos, hepatite, encefalopatia e também alterações cardiovasculares (ALVAREZ et. al., 2017; BURT et. al., 2017).

Em relação à infecção com Zika, a maioria dos casos transcorre de maneira assintomática ou com sintomatologia dengue-like. No entanto, recentemente, novas síndromes têm sido descritas, como a síndrome de Guillain-Barrè em adultos e, em neonatos, a síndrome congênita com diversas complicações incluindo microcefalia, alterações oftalmológicas e de audição (NGONO \& SHRESTA, 2018). Uma vasta gama de células 
humanas pode ser infectada por esses vírus, tais como hepatócitos, fibroblastos, células endoteliais e células dendríticas como os primeiros alvos e, posteriormente, células do sistema imune inato e humoral (DURBIN et al., 2008; KOU et al., 2008; GANDINI et al., 2011, YOUNG et al., 2014).

O acometimento do sistema cardiovascular foi descrito nas infecções causadas por arbovírus há mais de um século. Foi relatado inicialmente em 1822 em indivíduos infectados com febre amarela (YFV) (Oliveira \& Ferreira, 2018) e, em 1965 Thiruvengadam e colaboradores descreveram pela primeira vez sintomas de bradicardia e hipotensão em indivíduos infectados com CHIKV (THIRUVENGADAM et al., 1965; NAGARATNAM et al. 1973).

Uma revisão sistemática da literatura sobre trabalhos envolvendo comprometimento cardiovascular após infecção por CHIKV, publicada por Alvarez e colaboradores, descreve que, após o comprometimento osteoarticular, registrado em 97,1\% dos artigos selecionados, o comprometimento cardiovascular é o segundo sintoma mais descrito. Aproximadamente $50 \%$ dos trabalhos indicaram comprometimento do sistema cardiovascular com hipotensão, choque, arritmias, miocardites, falência cardíaca, entre outros. No entanto, poucos deles tiveram como foco exclusivo o estudo do comprometimento cardiovascular durante a infecção (ALVAREZ et. al., 2017).

Nas infecções por Zika vírus existem relatos de comprometimento cardiovascular com perigosa condição do ritmo cardíaco (fibrilação atrial) e possível insuficiência cardíaca (HUSSAIN et al., 2018). O ZIKV é um arbovírus pertencente a mesma família, Flaviviridae, dos vírus causadores de complicações cardiovasculares, como YFV, DENV e o vírus do Oeste do Nilo (WNV). O fato de as infecções em adultos serem, na maioria das vezes, assintomáticas ou leves, nos leva a pensar na possibilidade dessas complicações serem subdiagnosticadas na prática clínica (KRITTANAWONG et. al., 2016). Dessa maneira, investigações envolvendo o ZIKV são extremamente importantes, visto a significância em termos de saúde pública que esta infecção adquiriu nos últimos anos.

Após as epidemias de 2015 com ZIKV na América Latina, abriu-se um leque de novas descobertas relacionadas a um vírus considerado, até então, de pouca importância epidemiológica. Foram descobertas novas vias de transmissão, como a transplacentária e a sexual, e foram descritas novas síndromes causadas em decorrência da infecção, como, por exemplo, a síndrome congênita e a síndrome de Guillain-Barrè (NGONO \& SHRESTA, 2018). Disfunções endoteliais, característica de diferentes doenças cardiovasculares, também têm sido amplamente descritas e estudadas no desenvolvimento da patogênese de várias 
doenças infecciosas, dentre elas a dengue (VERVAEKE; VERMEIRE; LIEKENS, 2015).

Em alguns pacientes com dengue, o curso da doença pode evoluir para quadros mais graves conhecidos como a febre hemorrágica (DHF - do inglês dengue hemorragic fever) e síndrome do choque da dengue (DSS - dengue shock syndrome) (GUZMAN \& KOURI, 2004). Dentre as diversas alterações observadas na DHF e DSS, observam-se alterações da permeabilidade vascular com extravasamento de plasma no ambiente microvascular. As explicações recaem sobre resposta imunológica exacerbada do hospedeiro à infecção, com altos níveis de citocinas inflamatórias no soro dos pacientes (GUZMAN \& KOURI, 2004, PEYREFITTE et. al., 2006). Entretanto, temos que considerar a possibilidade de ações diretas do vírus nas células endoteliais vasculares.

O sistema vascular é constituído por um circuito fechado de tubos, com estrutura diferenciada para transportar o sangue com velocidade e pressão ideais para perfusão adequada dos tecidos. Cada segmento desse circuito, ou seja, cada tipo de vaso sanguíneo apresenta características morfofisiológicas específicas, correspondente às funções que exercem (AIRD, 2007). Essas diferenças estruturais e funcionais permitem a divisão dos vasos em artérias, arteríolas, capilares, vênulas e veias (AIRD, 2007).

As artérias possuem paredes mais fortes, com uma camada média mais espessa, constituída de grande quantidade de fibras elásticas e células musculares. A camada mais interna da artéria é formada por células endoteliais e a mais externa, chamada de camada adventícia, possui principalmente tecido conjuntivo. O sangue circula pelas artérias sob alta pressão e velocidade. A aorta, a artéria de maior calibre do corpo, acomoda todo o volume de sangue ejetado a cada sístole cardíaca. Essa complacência, ou capacidade das artérias, em aumentar o seu diâmetro vascular, é chamada de distensibilidade vascular. Devido a elasticidade arterial, as artérias conseguem retornar ao seu diâmetro inicial à medida que o sangue flui para o próximo segmento vascular. A complacência e a elasticidade aórtica transformam o fluxo sanguíneo intermitente, gerado pelos batimentos cardíaco, em fluxo contínuo para o restante da circulação (KAWANO et al., 2009).

Como as características acima descritas são importantes para manutenção do fluxo sanguíneo ideal, alterações na parede vascular da aorta, ou de outras artérias, em decorrência de doenças ou do processo de envelhecimento, também têm sido alvos de vários estudos (OLIVER et al., 2014; BLOUGH et al., 2007).

Considerando os conceitos citados, a pressão arterial é determinada pelo débito cardíaco e pela resistência vascular periférica. Portanto, aumento na resistência pode resultar em maiores valores de pressão arterial (NEVES et al., 2012). Quando a pressão arterial 
sistólica é igual ou superior a $140 \mathrm{mmHg}$ e/ou a pressão diastólica é igual ou superior a 90 mmHg, caracteriza-se a hipertensão arterial (WHO, 2021). Por outro lado, quedas significativas da resistência vascular podem levar ao choque, com hipoperfusão tecidual, como. Acontece, por exemplo, na sepse (KANDASAMY et al., 2011).

O endotélio, que recobre a camada interna de todo o sistema vascular, desde o coração e passando por todos os tipos de vasos, funciona como um sensor, adaptado às características do ambiente local. As células endoteliais apresentam forte integração com as células do músculo liso vascular, através das junções intercelulares - entre as células endoteliais ou entre essas células endoteliais e as células musculares lisas (AIRD, 2007; AIRD, 2008; GRIFFITH; CHAYTOR; EDWARDS, 2004).

A importância do óxido nítrico (NO) e seu papel determinante como mediador de várias funções do endotélio começaram a ser descritos por Furchgott e Zawadzki, em 1980. Estes pesquisadores verificaram que a presença do endotélio era essencial para o efeito vasodilatador da acetilcolina em anéis de aorta de coelho e concluíram que a acetilcolina agia no receptor muscarínico da célula endotelial, estimulando a produção de um fator relaxante que induzia o relaxamento das células do músculo liso vascular (FURCHGOTT \& ZAWADZKI, 1980).

O endotélio participa do controle do tono vascular através da produção de mediadores químicos que irão induzir uma resposta vasoconstritora (prostaglandina - $\mathrm{PGG}_{2}$, endotelina1, angiotensina II) ou uma resposta vasodilatadora (prostaglandinas $\mathrm{PGE}_{2}, \mathrm{PGI}_{2}, \mathrm{NO}$ e o fator hiperpolarizante derivado do endotélio - EDHF). Existe, em condições fisiológicas, um equilíbrio na produção desses mediadores. No entanto, uma alteração desta produção pode desencadear ou contribuir para a disfunção endotelial presente em diversas doenças (SIVITZ et al., 2007; STAPLETON et al., 2008).

A expansão das epidemias de CHIKV e ZIKV têm representado uma grande ameaça à saúde pública com considerável impacto socioeconômico nos países onde elas ocorrem. Esforços crescentes no campo da pesquisa têm sido feitos para se melhor compreender as lacunas existentes na patogênese da doença. Sendo assim, pesquisas voltadas para abordagens envolvendo as arboviroses são de grande importância na medida em que os resultados gerados podem contribuir não só para o desenvolvimento de vacinas eficazes e identificação de possíveis alvos antivirais, mas também para um melhor manejo clínico dos pacientes no futuro.

Modelos animais aperfeiçoados que contribuam com a investigação da patologia desses arbovírus podem abrir caminhos para o desenvolvimento de vacinas e moléculas 
antivirais. Diante do exposto, nossa proposta de estudo é a abordagem de tema ainda pouco explorado pela literatura atual, que são as manifestações cardiovasculares decorrentes da infecção com o arbovírus CHIKV, e os mecanismos envolvidos, abrindo perspectivas de novas investigações e descobertas acerca dessas doenças.

\subsection{PROCESSO INFLAMATÓRIO E ESTRESSE OXIDATIVO NA INFECÇÃO VIRAL}

O processo inflamatório está envolvido no desenvolvimento de complicações cardiovasculares em várias condições clínicas, através de reações inflamatórias que compreendem uma sequência de eventos coordenados pelo sistema imunológico. Estão envolvidas interações complexas entre células inflamatórias, como neutrófilos, linfócitos, monócitos/macrófagos, e células vasculares, por exemplo. Tais interações resultam em aumento da produção tecidual de mediadores solúveis, bem como proteínas do sistema complemento, quimiocinas, citocinas, espécies reativas de oxigênio (EROs), aminas vasoativas, entre outros, acompanhado pelo aumento da expressão de moléculas de adesão celular em leucócitos circulantes e células endoteliais (FULLERTON \& GILROY, 2016).

As citocinas e outros elementos produzidos por células dos componentes do sistema imunológico inato e adaptativo, são importantes para o processo inflamatório e ativação do sistema de defesa. Estas são importantes na modulação da inflamação, desencadeando e regulando mecanismos como o recrutamento de neutrófilos e monócitos para o local da lesão (LIDDIARD et al., 2011), o aumento na permeabilidade vascular e a geração de EROs durante a resposta inflamatória (ESPINOSA, 2012).

A produção fisiológica do NO é realizada pelas enzimas óxido nítrico sintase (NOS), que são expressas em vários tecidos do organismo (FORSTERMANN \& SESSA, 2011). Há evidências importantes de que a infecção por CHIKV modula a expressão e liberação de citocinas. Além disso, atrelada ao processo inflamatório, a superprodução de NO está principalmente relacionada à família das sintases de óxido nítrico (NOS), sendo elas a óxido nítrico sintase neuronal (nNOS/NOS1) e a endotelial (eNOS/NOS3), consideradas constitutivas, e a induzível (iNOS/NOS2). Contudo, a iNOS é responsável por maior produção de NO e por períodos prolongados, quando comparada às outras isoformas (MONCADA \& HIGGS, 1993; STUEHR \& GRIFFITH, 1992), e é geralmente expressa por células fagocíticas inflamatórias, as quais desempenham a função de defesa contra bactérias, fungos e parasitas (GRANGER et al., 1988; UMEZAWA et al., 1997; NATHAN et al., 1997). 
O NO, como já foi dito, exerce papel fundamental no controle do tônus vascular, contrapondo-se às ações dos mediadores contráteis liberados pelo próprio endotélio ou advindos da circulação (GAO, 2009). Outros mediadores derivados do endotélio podem também exercer papel importante no controle da resposta vasomotora (FELETOU; HUANG; VANHOUTTE, 2011).

A NOS é induzida em uma variedade de infecções experimentais de vírus em modelos animais, incluindo o vírus do herpes simplex tipo 1 (HSV-1), vírus da raiva e vírus pneumotrópico e cardiotrópico, o vírus da gripe, entre outros (AKAIKE; SUGA; MAEDA, 1998; AKAIKE; MAEDA, 1999; KOPROWSKI et al., 1993; FUJII; AKAIKE; MAEDA, 1999). A expressão de iNOS também é observada em doenças humanas causadas pelo vírus da imunodeficiência humana-1 (HIV-1) e vírus da hepatite B (HBV) (BUKRINSKY et al., 1995; MAJANO et al., 1998). A iNOS também é expressa por macrófagos e células epiteliais brônquicas em tecidos pulmonares infectados com vírus influenza em camundongos (AKAIKE \& MAEDA, 1999; AKAIKE et al., 1996). Sendo assim, há evidências que mostram expressão majoritária da iNOS durante as respostas do hospedeiro à replicação viral in vivo.

Ocorre também regulação negativa da expressão de iNOS por algumas citocinas como, por exemplo, interleucinas IL-4 e IL-10 e fator de crescimento de transformação- $\beta$ (CUNHA; MOHCADA; LIEW, 1992; BOGDAN et al., 1994). Além disso, essas citocinas supressoras podem reduzir a produção de NO indiretamente por meio da indução de arginase (CORRALIZA et al., 1995; SONOKI et al., 1997), diminuindo o substrato (1-arginina) para iNOS. Estudos também demonstraram que, em um modelo de influenza, a indução de IL-4 parece estar inversamente relacionada à indução de IFN- $\gamma$ e iNOS em pulmões infectados por vírus. Isto sugere regulação negativa da superprodução de NO por IL-4, visto que essas citocinas são induzidas por respostas de células T auxiliares tipo 2 (Th2), e que a expressão de iNOS pode ser regulada por um equilíbrio Th1-Th2 envolvido na resposta imune do hospedeiro ao vírus intruso (AKAIKE \& MAEDA, 1999).

Assim, o NO apresenta funções complexas nas respostas imunológicas do hospedeiro contra infecções virais. Um dos mecanismos de patogênese da infecção viral é mediado por eventos biológicos afetados pelo NO. Destaca-se a contribuição do estresse oxidativo induzido pelo NO, visto que a citotoxicidade induzida pelo NO gera lesão oxidativa que pode causar, além de imunossupressão e agravamento da patogênese, disfunções celulares e orgânicas (AKAIKE \& MAEDA, 2000).

Em infecções virais, o $\mathrm{NO}$ e $\mathrm{ONOO}^{-}$, que são moléculas atuantes na defesa primária 
do hospedeiro podem causar danos oxidativos não específicos nos tecidos infectados, levando a diversos eventos patológicos, visto que o vírus não pode ser confinado a áreas limitadas de defesas específicas do hospedeiro mediadas por fagócitos, $\mathrm{NO}_{\text {e }} \mathrm{O}_{2}^{\bullet-}($ AKAIKE; SUGA \& MAEDA, 2000).

O NO é uma molécula mensageira chave que possui várias funções no organismo. Além das funções já citadas nos tópicos anteriores, o NO participa da modulação de processos cognitivos de aprendizado e memória (ZHOU \& ZHU, 2009), da regulação neural da pressão arterial (ALLY; NAULI; MAHER, 2005), da regulação da transcrição gênica (KHAN et al., 1996), e da tradução do mRNA (PANTOPOULOS \& HENTZE, 1995). Um importante mecanismo de inativação do $\mathrm{NO}$ é a sua reação com o ânion superóxido $\left(\mathrm{O}_{2}{ }^{\bullet-}\right)$, resultando na formação de um potente agente oxidante, o peroxinitrito $\left(\mathrm{ONOO}^{-}\right)$. Esse composto pode causar dano oxidativo, nitração e S-nitrosilação de proteínas, lipídios e DNA. Essas reações podem inativar essas biomoléculas, acionando vias de degradação ou até mesmo de morte celular (PACHER; BECKMAN; LIAUDET, 2007). 
2HIPÓTESE 


\section{HIPÓTESE}

A infecção com o arbovírus CHIKV, assim como ocorre com DENV, YFV e WNV, também pode promover comprometimento vascular, por ações diretas dos arbovírus em células endoteliais e por mecanismos que envolvem estresse oxidativo e alteração na produção e sinalização do óxido nítrico (NO), fatores amplamente relacionados às doenças cardiovasculares.

\section{INFECÇÃO COM CHIKV}

$\downarrow$

ATIVAÇÃO DA VIA DA ÓXIDO NÍTRICO SINTASE INDUZIDA

$\downarrow$

ESTRESSE OXIDATIVO

$\downarrow$

DISFUNÇÃO VASCULAR

Figura 1 - Esquema representativo da hipótese. 
3 OBJETIVOS 


\section{OBJETIVOS}

\subsection{OBJETIVO GERAL}

Investigar os efeitos da infecção com o arbovírus CHIKV na função vascular e os mecanismos moleculares e funcionais envolvidos.

\subsection{OBJETIVOS ESPECÍFICOS}

- Estabelecer modelo animal de infecção com o arbovírus CHIKV para o estudo das alterações cardiovasculares.

- Avaliar, usando modelos experimentais in vivo e in vitro, se o arbovírus CHIKV interfere com fatores chave envolvidos na disfunção vascular, tais como marcadores de inflamação,geração de Espécies Reativas de Oxigênio (EROs) e vias relacionadas à sinalização do NO.

- Demonstrar os mecanismos moleculares envolvidos nas alterações vasculares funcionais observadas. 
4MÉTODOS 


\section{MÉTODOS}

\subsection{ANIMAIS}

Todos os procedimentos experimentais foram aprovados pela Comissão de Ética no Uso de Animais (CEUA) da Faculdade de Medicina de Ribeirão Preto da Universidade de São Paulo (Protocolo $\mathrm{n}^{\circ}$ 171/2019), que segue os princípios éticos em experimentação animal adotado pelo Conselho Nacional de Controle de Experimentação Animal (CONCEA).

Foram utilizados camundongos, machos, C57BL/6J (tipo selvagem, Wild Type - WT) adquiridos do Biotério Central da Universidade de São Paulo - Campus de Ribeirão Preto, com 6 semanas de idade. Os camundongos foram mantidos durante todo o período experimental em caixas de polipropileno [comprimento (30) x largura (20) x altura (13) cm e 5 animais por caixa], acondicionadas em ambiente com temperatura controlada de $22 \pm 2{ }^{\circ} \mathrm{C}$, umidade de 50 $\pm 5 \%$ e ciclos claro-escuro de 12 horas (h), com livre acesso a água e alimento (Nuvilab CR-1 Irradiada).

\subsection{INFECÇÃO COM O CHIKV}

Camundongos WT com 6 semanas de idade foram infectados com o vírus Chikungunya

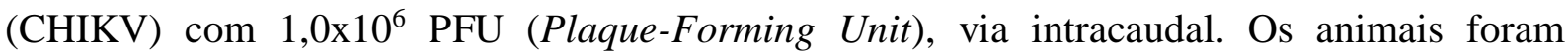
divididos em dois grupos experimentais: 1) camundongos que receberam infusão de veículo (virus-free mock medium, mock inoculated-WT_Mock); 2) camundongos que foram infectados com CHIKV (WT_CHIKV).

Os animais WT_Mock foram infundidos somente com o meio de cultura. Para a padronização do modelo animal, as avaliações foram realizadas 24, 48 e $72 \mathrm{~h}$ após a infecção. A eutanásia dos animais ocorreu após os tempos utilizados para a padronização.

\subsection{ESTUDO DA REATIVIDADE VASCULAR EM ANÉIS DE AORTA ISOLADOS}

Após anestesia com isoflurano e eutanásia dos animais, as aortas torácicas foram removidas e colocadas em placas de Petri contendo solução nutriente de Krebs-Henseleit modificada, a $4{ }^{\circ} \mathrm{C}$, com a seguinte composição (em $\mathrm{mM}$ ): $\mathrm{NaCl}, 130 ; \mathrm{KCl}, 4,7 ; \mathrm{KH}_{2} \mathrm{PO}_{4}, 1,1$; $\mathrm{MgSO}_{4}, 1,1 ; \mathrm{NaHCO}_{3}, 15$; EDTA, 0,03; $\mathrm{CaCl}_{2}, 1,6$; Glucose, 5,5 (Lobato et al., 2012). A porção mediana da aorta torácica foi dividida em 4 anéis de $2 \mathrm{~mm}$ de comprimento sem o tecido adiposo perivascular (PVAT). Os anéis com endotélio foram montados em miógrafo (modelo 620M; Danish Myo Technology - DMT, Copenhagen, Denmark) para estudo da geração de força 
isométrica. Os anéis foram colocados entre ganchos, um fixo e outro conectado a um transdutor de sinal acoplado a um computador. As preparações permaneceram sob tensão de 5 milinewtons $(\mathrm{mN})$, por 30 min para estabilização, nas cubas do miógrafo contendo solução de KrebsHenseleit modificada, gaseificada com $95 \%$ de oxigênio $\left(\mathrm{O}_{2}\right)$ e $5 \%$ de dióxido de carbono $\left(\mathrm{CO}_{2}\right)$ e aquecida à $37^{\circ} \mathrm{C}$, com trocas de solução nutriente e ajuste de tensão a cada 10 min.

Após o período de estabilização, as artérias foram estimuladas com cloreto de potássio ( $\mathrm{KCl} 120 \mathrm{mM}$ ), com a finalidade de se avaliar a integridade funcional. Após novo período de lavagem e estabilização por mais $30 \mathrm{~min}$, a integridade do endotélio foi testada avaliando-se o relaxamento à acetilcolina [( $\mathrm{ACh})$ vasodilatador dependente de endotélio, concentração $10^{-6} \mathrm{M}$ ] em vasos pré-contraídos com fenilefrina [(FEN) agonista alfa adrenérgico, na concentração $10^{-}$

$\left.{ }^{6} \mathrm{M}\right]$. A ausência de relaxamento à ACh foi critério para confirmação da ausência de endotélio. Dessa maneira, os protocolos experimentais foram realizados em vasos com e sem endotélio.

\subsubsection{Protocolo experimental}

Para avaliar os efeitos ex vivo da infecção pelo CHIKV na função vascular, utilizamos segmentos aórticos com endotélio intacto e também sem endotélio após a remoção mecânica, ambos sem o tecido adiposo perivascular (PVAT), provenientes de camundongos infectados $\left(1,0 \times 10^{6} \mathrm{PFU}\right.$ por $\left.48 \mathrm{~h}\right)$ para realização de curvas concentração-resposta cumulativas para FEN e ACh. As respostas de contração a FEN foram expressas em $\mathrm{mN}$ e as respostas a $\mathrm{ACh}$, como porcentagem de relaxamento em relação aos valores de pré-contração induzidos por FEN.

Além disso, para verificar os efeitos da infecção por CHIKV na geração de EROs foram utilizadas ferramentas farmacológicas tais como Tiron $\left(10^{-5} \mathrm{M}\right.$ - sequestrador de EROs), L- NAME $\left(10^{-4} \mathrm{M}\right.$, inibidor não-seletivo da NOS). Também foram realizadas curvas concentração-efeito de caráter cumulativo para FEN $\left(10^{-10}-10^{-4} \mathrm{M}\right)$ em segmentos aórticos com endotélio intacto e sem endotélio.

\subsection{ENSAIOS IN VITRO}

4.4.1 Cultura de células endoteliais (EA.hy926) e infecção viral

A definição da multiplicidade de infecção (MOI - multiplicity of infection), foi realizada através de ensaios com soluções não diluídas com grande número de partículas virais, reduzindo a variabilidade estocástica. $\mathrm{O}$ número médio de vírus que podem infectar uma célula foi estimado como a razão entre o número de vírus em solução e o número de células plaqueadas (MOI) (BROWN \& BIDLE, 2014).

Foram utilizadas células humanas imortalizadas derivadas de veia umbilical humana 
(EA.hy926), em cultura. As células foram cultivadas em placas de 6 poços e infectadas com os vírus e/ou veículo, com multiplicidade de infecção (MOI) de 1,0.

\subsubsection{Análise de expressão proteica por Western blotting}

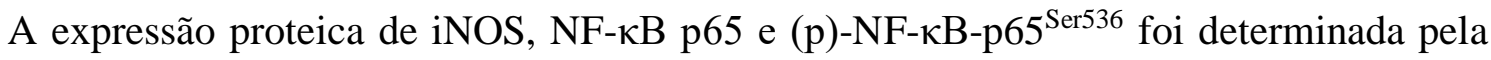
técnica de Western Blotting. Aortas torácicas de camundongos dos grupos WT_Mock e WT_ CHIKV foram isoladas, o tecido adiposo perivascular foi removido e as mesmas foram congeladas em nitrogênio líquido e em seguida foram pulverizadas. Também foram utilizadas células endoteliais humanas (EA.hy926) infectadas e expostas ao veículo para avaliação da expressão proteica do lisado celular da molécula de adesão intracelular-1 (ICAM-1). Todas as amostras foram homogeneizadas em tampão de lise gelado.

Os extratos teciduais e celulares em tampão de lise foram centrifugados a 13.000 rpm, a 4 ${ }^{\circ} \mathrm{C}$, por 15 min para a remoção do material insolúvel. Após a centrifugação, o conteúdo proteico total foi quantificado, utilizando o método de Bradford (Bradford, 1976). Em seguida, as amostras foram tratadas com tampão de Laemmli contendo ditiotreitol $200 \mathrm{mM}$ e $50 \mu \mathrm{g}$ de proteína total foram submetidas à eletroforese em gel de poliacrilamida (12\%) com dodecil sulfato de sódio (SDS) em aparelho para mini gel (BioRad, Hercules, USA). Em cada gel havia um marcador com pesos moleculares de valores estabelecidos.

A transferência das proteínas separadas no gel para a membrana de PVDF, após ativação com metanol $(\mathrm{CH} 3 \mathrm{OH})$, foi feita eletricamente, por meio de aparelho da BioRad, por $1 \mathrm{~h}$, a 100 V. O tampão foi acrescido de SDS 0,1\% para melhorar a eluição de proteínas de alto peso molecular. A membrana de nitrocelulose foi incubada com uma solução bloqueadora TBS- T [Tris $10 \mathrm{mM}, \mathrm{NaCl} 150 \mathrm{mM}$ e Tween 20 0,02\%] contendo 5\% de albumina bovina sérica (BSA), a $25{ }^{\circ} \mathrm{C}$, durante $1 \mathrm{~h}$ para reduzir a ligação inespecífica de proteínas na membrana. As membranas foram incubadas com anticorpos específicos para avaliar proteínas da via do NF$\kappa \mathrm{B}$.

A incubação com anticorpo primário foi feita com solução bloqueadora TBS-T contendo $1 \%$ de BSA overnight na geladeira $\left(4^{\circ} \mathrm{C}\right)$ e a concentração de cada anticorpo variou de 1:250 a 1:10000. Em seguida, as membranas foram lavadas com a solução bloqueadora por $1 \mathrm{~h} \mathrm{e}$, posteriormente, incubadas com o segundo anticorpo, conjugado com peroxidase por $1 \mathrm{~h}$, em temperatura ambiente. As bandas foram detectadas após incubação com Luminata (Western Blotting Detection Reagent - Millipore Corporation). A emissão de luz foi detectada e visualizada por fotodocumentador ImageQuant 350 (GE Healthcare Piscata Way, NJ, EUA). A 
intensidade das bandas foi quantificada por densitometria óptica através da utilização de programa de análise de intensidade de bandas (Image ${ }^{\circledR}$, NIH, USA). Os anticorpos utilizados estão descritos na tabela a seguir:

Tabela 1 - Anticorpos utilizados nos ensaios de Western blotting.

\begin{tabular}{|c|c|c|}
\hline Alvo & Diluição & Marca \\
\hline iNOS & $1: 250$ & Sigma-Aldrich (SAB4502011-100UG) \\
\hline$\beta$-actina & $1: 10000$ & Sigma-Aldrich (A3854-200UL) \\
\hline NF- $\kappa$ B p65 & $1: 500$ & Cell Signaling Technology (\#8242S) \\
\hline (p)-NF- $\kappa B-p 65^{\text {Ser536 }}$ & $1: 500$ & Cell Signaling Technology (\#3033S) \\
\hline ICAM-1 (EA.hy926) & $1: 500$ & Santa Cruz Biotechnology (sc-8439) \\
\hline
\end{tabular}

\subsection{QUANTIFICAÇÃO DE CITOCINAS POR ELISA}

A quantificação da citocina pró-inflamatória IL-6 foi realizada no soro dos animais e no sobrenadante de células endoteliais humanas (EA.hy926) por método imunoenzimático (ELISA, do inglês Enzyme-Linked ImmunonoSorbent Assay) que se baseia em reações antígenoanticorpo detectáveis através de reações enzimáticas.

Para obtenção do soro, o sangue foi coletado por punção cardíaca nos animais infundidos com veículo e CHIKV. O sangue foi centrifugado a $1.500 \mathrm{rpm} \mathrm{a} 4{ }^{\circ} \mathrm{C}$ por $15 \mathrm{~min}$. As amostras de soro foram armazenadas em freezer $-80^{\circ} \mathrm{C}$ até a realização do experimento.

O ensaio para quantificação de IL-6 foi realizado conforme descrito pelo fabricante dos kits (R\&D Systems, Minneapolis, MN, USA). Em placas de 96 poços foram adicionados 50 $\mu \mathrm{L} /$ poço de soluções contendo os anticorpos de captura para cada citocina (anti- IL-6 murino $800 \mathrm{ng} / \mathrm{ml}$ ). Os anticorpos foram diluídos em tampão fosfato salino (PBS) acrescido de 10\% de soro fetal bovino (SFB) e incubados nas placas por $12 \mathrm{~h}$ à $4^{\circ} \mathrm{C}$.

Posteriormente, as placas foram lavadas por três vezes com PBS/Tween-20 (0,05\%). As ligações não específicas foram bloqueadas com $100 \mu \mathrm{L}$ de PBS acrescido de $1 \%$ de BSA, por 120 min, em temperatura ambiente. As amostras e diferentes concentrações de IL-6 - para confecção de curva padrão - em volume final de $50 \mu \mathrm{L} /$ poço foram colocadas nas placas e incubadas por $12 \mathrm{~h}$ à $4{ }^{\circ} \mathrm{C}$.

Após esse período, as placas foram lavadas com PBS/Tween-20 (0,05\%) e $50 \mu \mathrm{L}$ dos 
anticorpos de detecção biotinilados específicos para cada citocina foram adicionados. Após 1 $\mathrm{h}$, as placas foram lavadas com PBS/Tween-20 (0,05\%) e estreptoavidina-HRP (fornecida pelo fabricante do kit e diluída 1:250) foi adicionada aos poços. Após 30 min de incubação, as placas foram lavadas com PBS/Tween-20 (0,05\%), e $100 \mu \mathrm{L}$ do substrato tetrametilbenzidina - 1 $\mathrm{mg} / \mathrm{mL}$, acrescido de $0,06 \%$ de peróxido de hidrogênio, foram colocados em cada poço. As placas foram incubadas por 15 min em temperatura ambiente. A reação foi interrompida com $50 \mu \mathrm{L}$ de ácido sulfúrico $(1 \mathrm{M})$ e a densidade óptica aferida à $450 \mathrm{~nm}$ em espectrofotômetro (FlexStation 3, Molecular Devices, San Jose, CA, USA). Os resultados foram expressos em picogramas/mL.

\subsection{ESTUDO DA GERAÇÃO DE ESPÉCIES REATIVAS DE OXIGÊNIO}

4.6.1 Medida da produção de ânion superóxido $\left(\mathrm{O}_{2}{ }^{\bullet-}\right)$ por Lucigenina

A geração de ânion superóxido $\left(\mathrm{O}_{2}{ }^{\circ}\right)$, em aortas torácicas e células EA.hy926, foi medida por ensaio de quimioluminescência, utilizando a lucigenina como aceptor de elétrons de dinucleótido de nicotinamida e adenina (NADH) como substrato. O procedimento foi realizado em aortas de camundongos C57BL/6J infectados ou não com CHIKV (1,0x10 6 PFU) e em células EA.hy926, após 24, 48 e 72 h, as quais foram homogeneizadas em tampão de trabalho (50 mM KH2PO4, $1 \mathrm{mM}$ EGTA e $150 \mathrm{mM}$ sacarose, $\mathrm{pH}$ 7.4). Os ensaios foram realizados com $100 \mu \mathrm{l}$ de amostra, lucigenina $(5 \mu \mathrm{M})$, NADH $(0,1 \mathrm{mM})$ e tampão de trabalho. A geração de $\mathrm{O}_{2} \bullet$ foi expressa em unidades relativas de luminescência pelo peso seco do tecido em relação à intensidade do controle.

\subsubsection{Medida da produção de peróxido de hidrogênio $\left(\mathrm{H}_{2} \mathrm{O}_{2}\right)$ por Amplex Red}

A produção de $\mathrm{H}_{2} \mathrm{O}_{2}$ foi avaliada em alíquotas de $50 \mu \mathrm{L}$ dos extratos teciduais e do sobrenadante celular, usando kit para dosagem de $\mathrm{H}_{2} \mathrm{O}_{2}$, Amplex Red (Molecular Probes, Invitrogen). A fluorescência emitida foi medida nos comprimentos de excitação: $530 \mathrm{~nm}$ e emissão: $590 \mathrm{~nm}$. A curva padrão para $\mathrm{H}_{2} \mathrm{O}_{2}$ foi construída com o padrão do fabricante, em temperatura ambiente e utilizada para determinar a concentração de $\mathrm{H}_{2} \mathrm{O}_{2}$ das amostras. $\mathrm{O}$ resultado foi expresso com a média das concentrações absolutas de $\mathrm{H}_{2} \mathrm{O}_{2}$ detectadas nas amostras $(\mu \mathrm{M})$ corrigido pelo total proteínas totais.

\subsubsection{Avaliação de níveis de marcadores de estresse oxidativo - TBARS}


Um dos mecanismos de lesão no estresse oxidativo é a oxidação da camada lipídica da membrana celular, processo conhecido como lipoperoxidação (LPO). Os subprodutos oriundos dessa LPO podem ser detectados pelo ensaio que utiliza ácido tiobarbitúrico como reagente, através da técnica conhecida como TBARS (do inglês, thiobarbituric acid reactive substances).

Assim, avaliamos se a infecção com CHIKV nas células endoteliais (EA.hy 926) favorece a geração desses marcadores de estresse oxidativo com alteração dos níveis de substâncias reativas ao ácido tiobarbitúrico (TBARS).

4.6.4 Medida da produção de nitrito $\left(\mathrm{NO}_{2}^{-}\right)$pelo ensaio de Griess

A produção de $\mathrm{NO}$ foi mensurada indiretamente através da concentração de $\mathrm{NO}_{2}{ }^{-}$ (nitrito) no soro dos animais WT_Mock e WT_CHIKV, acrescidos com nitrato redutase, em ausência de luz, à $37^{\circ} \mathrm{C}$, através do ensaio colorimétrico de Griess com posterior leitura em espectrofotômetro a $540 \mathrm{~nm}$. As concentrações de nitratos no soro dos animais, após serem infundidos, foram obtidas pela subtração dos valores de nitrito dos valores NOx (nitrito + nitrato).

\subsection{MEDIDA DA PRESSÃO ARTERIAL EM MODELO EXPERIMENTAL DE INFECÇÃO POR CHIKV POR PLETISMOGRAFIA DE CAUDA}

A pressão arterial sistólica foi determinada por método indireto em camundongos acordados, pela técnica de pletismografia de cauda. Os animais foram ambientados durante cinco dias antes da primeira medida de pressão arterial caudal, onde foram submetidos a período de adaptação que envolvia o aquecimento dos animais em uma placa aquecida a $31^{\circ} \mathrm{C}$ por $10 \mathrm{~min}$ e a contenção em cilindro de acrílico com abertura para o focinho e cauda, por $5 \mathrm{~min}$.

Após o procedimento de adaptação, os níveis pressóricos dos camundongos foram determinados com auxílio de oclusor, o qual foi ajustado à porção proximal da cauda eum cuff acoplado na porção distal, no sistema de aferição de pressão Coda 6 (Kent Scientific Corporation). O valor final da pressão arterial caudal de cada animal representa a média aritmética de três medidas sequenciais.

\subsection{ANÁLISES ESTATÍSTICAS}

Os resultados dos experimentos moleculares foram analisados pelo teste t de Student, teste de análise de variância uma (One-way ANOVA) $e$ de duas vias (Two-way ANOVA), seguido do pós-teste Bonferroni. Em resultados de reatividade vascular, as curvas concentração-efeito individuais foram plotadas em uma curva sigmoidal por análise de 
regressão não linear. Estas curvas, por sua vez, fornecem o valor de $p \mathrm{D} 2$ (logaritmo negativo dos valores de EC50 - concentração que produz 50\% da resposta máxima) e a resposta máxima. Os valores de $p \mathrm{D} 2$ e de resposta máxima foram comparados por meio da ANOVA seguida do teste de Bartlett para a homogeneidade das variâncias e teste de múltiplas comparações Bonferroni. O programa Prisma, versão 5.0 (GraphPad Software Inc., San. Diego, CA, USA) foi utilizado para analisar estes parâmetros. Os resultados foram expressos como média \pm erro padrão da média (E.P.M.). O nível de significância mínima aceitável foi p<0,05. 
5RESULTADOS 


\section{RESULTADOS}

\subsection{PADRONIZAÇÃO DO MODELO ANIMAL DE INFECÇÃO POR CHIKV}

5.1.1 Efeitos da infecção com CHIKV sobre as respostas contrátil à fenilefrina e dilatadora à acetilcolina em aortas torácicas de camundongos

Primeiramente, na padronização do modelo experimental, avaliamos o impacto da infecção com CHIKV em três períodos para definir tempo de infecção onde se evidenciariam efeitos vasculares. No tempo de 24 h pós-infecção não foram observadas alterações de reatividade vascular em animais infectados por CHIKV (Figuras 2A e 2B). Houve diminuição da resposta contrátil a fenilefrina em aortas dos camundongos infectados por CHIKV $48 \mathrm{~h}$ após infeçcão (Figuras 2E e 2F), efeito que se manteve 72 h após infecção (Figuras 2I e 2J). Além disso, nos tempos avaliados, não houve alteração da resposta vasodilatadora à acetilcolina (Figuras 2C, 2D, 2G, 2H, 2K, 2L). A tabela 1 mostra os efeitos da infecção por CHIKV nas aortas torácicas de camundongos sobre os valores de $p \mathrm{D}_{2}$ da fenilefrina e acetilcolina.

$24 \mathrm{~h}$
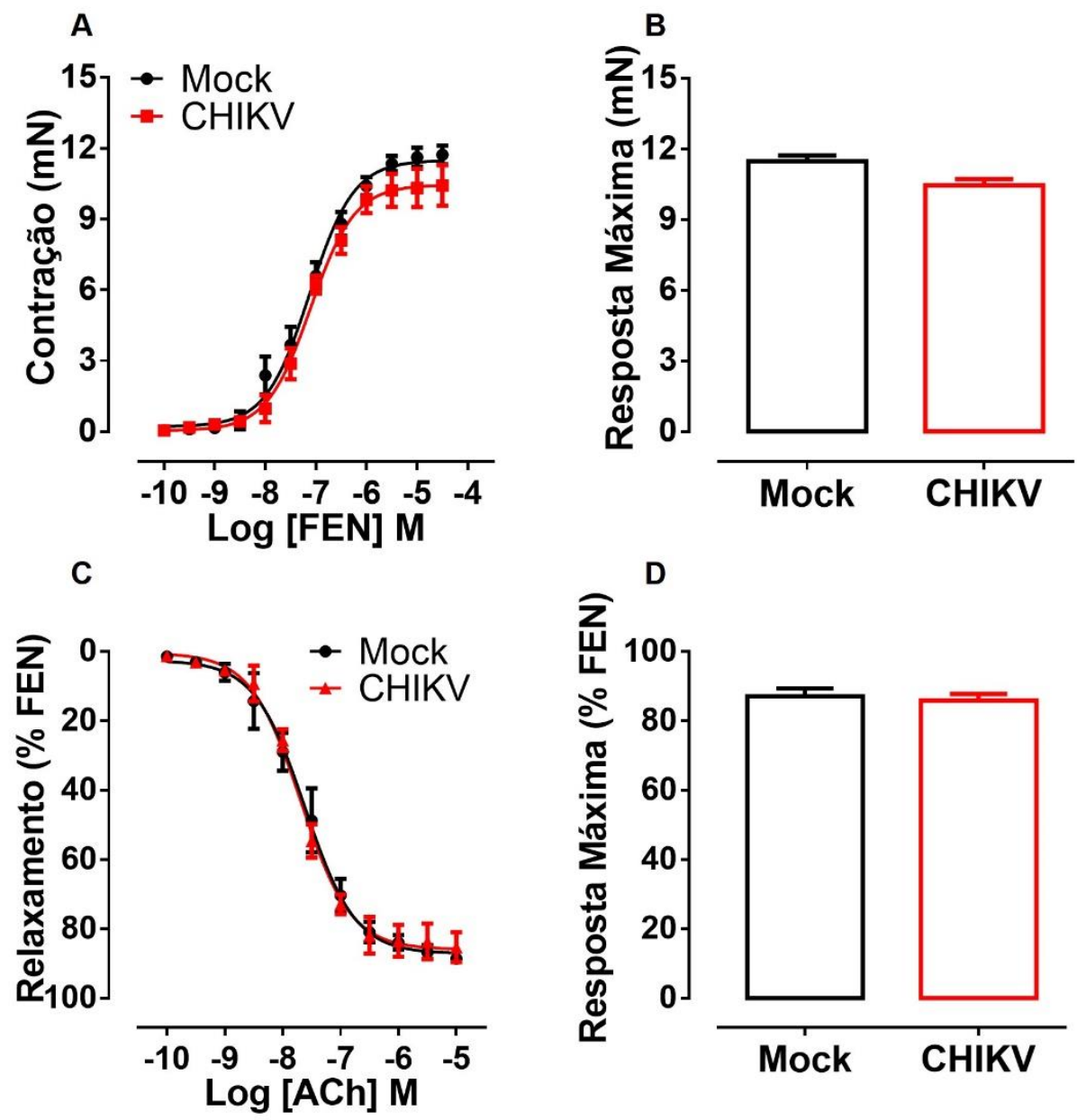


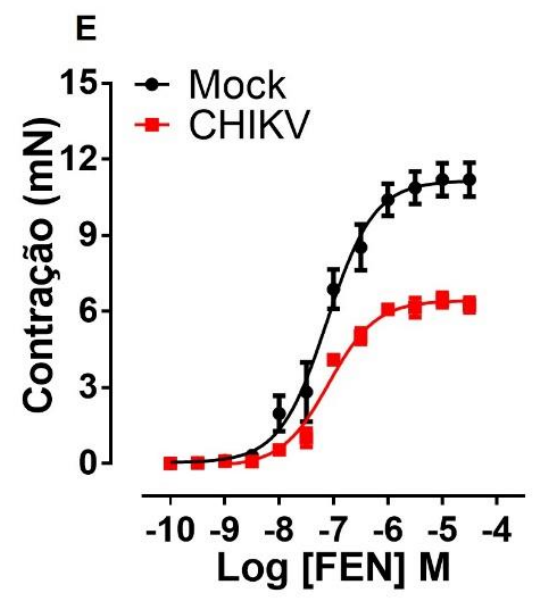

$48 \mathrm{~h}$
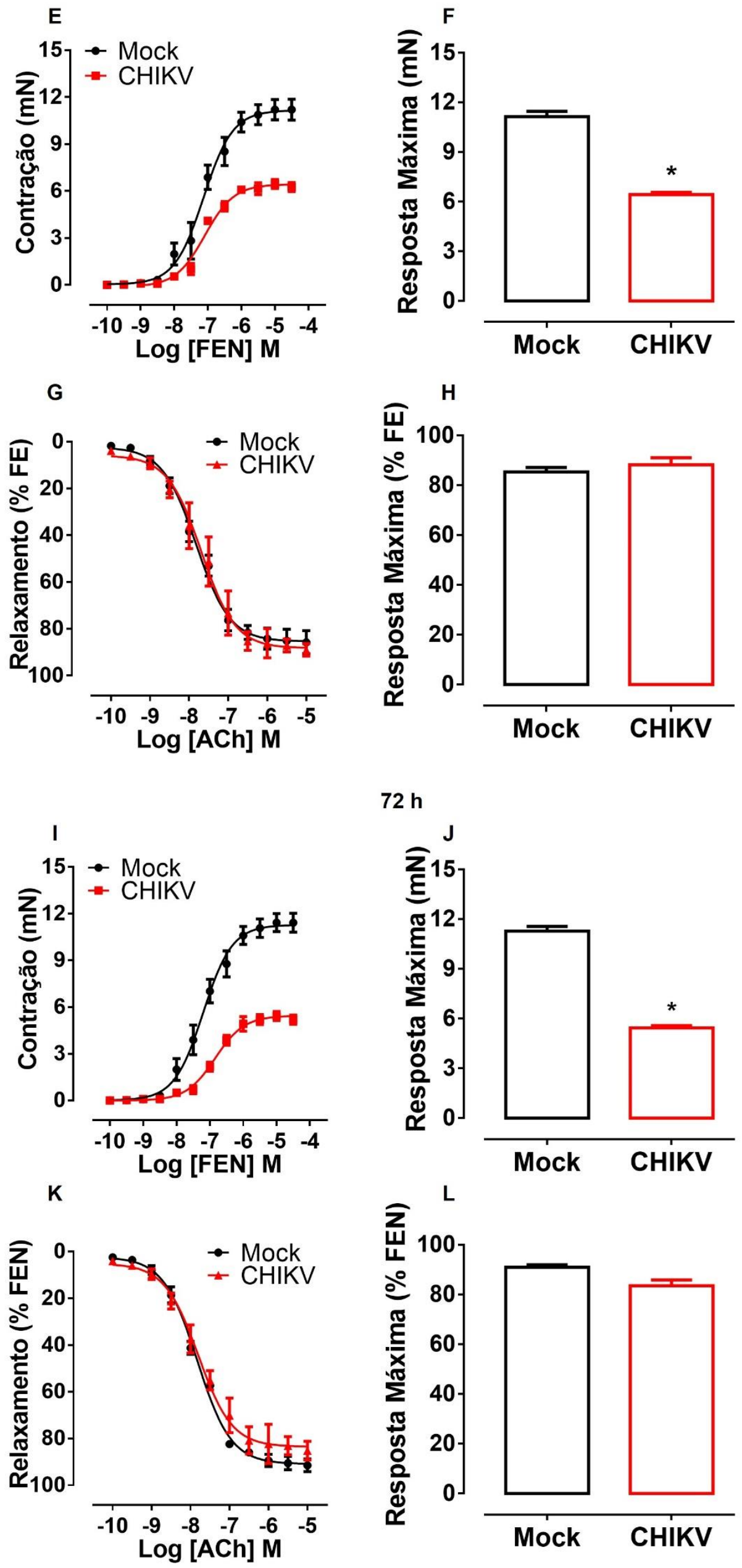
Figura 2. Curvas concentração-efeito cumulativas à fenilefrina (FEN) em anéis de aorta com endotélio de machos C57BL/6J infectados (WT_CHIKV) ou inoculados com veículo (WT_Mock). Os gráficos demonstram que, nos tempos de $48 \mathrm{~h}$ (E) e $72 \mathrm{~h}$ (I), a infecção com CHIKV reduziu as respostas vasculares a fenilefrina (FEN), mas não à acetilcolina ( $\mathrm{ACh}),(\mathrm{G}$ e $\mathrm{K})$. Resultados expressos como média \pm EPM. $\mathrm{O}$ gráfico de barras mostra a resposta máxima obtida nas curvas concentração-efeito. Foi utilizado o teste ANOVA de duas vias seguido do pósteste de Tukey e o teste t de Student, para análise estatística. $\mathrm{n}=5-6$ animais/grupo. WT: (Wild type - Camundongos selvagens).

Tabela 2. Valores de $\mathrm{p} D_{2}$ para FEN e ACh em aortas de camundongos WT_Mock e infectados com CHIKV nos tempos de 24, 48 e $72 \mathrm{~h}$.

\begin{tabular}{ccccccc}
\hline & \multicolumn{2}{c}{$\mathbf{2 4}$ h } & \multicolumn{2}{c}{$\mathbf{4 8}$ h } & \multicolumn{2}{c}{$\mathbf{7 2 ~ h}$} \\
\hline & FEN & ACh & FEN & ACh & FEN & ACh \\
\hline WT_Mock & $7,12 \pm 0,05$ & $7,61 \pm 0,07$ & $7,124 \pm 0,08$ & $7,82 \pm 0,06$ & $7,20 \pm 0,07$ & $7,82 \pm 0,03$ \\
WT_CHIKV & $7,10 \pm 0,07$ & $7,68 \pm 0,06$ & $7,08 \pm 0,05^{*}$ & $7,68 \pm 0,10$ & $6,84 \pm 0,06^{*}$ & $7,80 \pm 0,09$ \\
\hline
\end{tabular}

Os dados representam a média \pm S.E.M $\left(\mathrm{n}=5-6\right.$ animais /grupo). Teste $t$ de Student: $* \mathrm{p}<0,05 v s$. WT_Mock. $\mathrm{p} D_{2}$ : logaritmo negativo da $\mathrm{EC}_{50}$, FEN: fenilefrina, $\mathrm{ACh}$ : acetilcolina. WT: Wild type.

\subsection{AVALIAÇÃO DA GERAÇÃO DE ÂNION SUPERÓXIDO $\left(\mathrm{O}_{2}{ }^{\circ}\right)$}

No tempo de $48 \mathrm{~h}$ após infecção com CHIKV, houve aumento no sinal de quimioluminescência a lucigenina, sugerindo aumento na produção de ânion superóxido $\left(\mathrm{O}_{2}{ }^{*}\right)$ (Figura 3B). Não foi detectado alteração de $\mathrm{O}_{2} \bullet$ nos tempos de 24 h (Figura 3A) ou 72h (Figura $3 \mathrm{C})$.
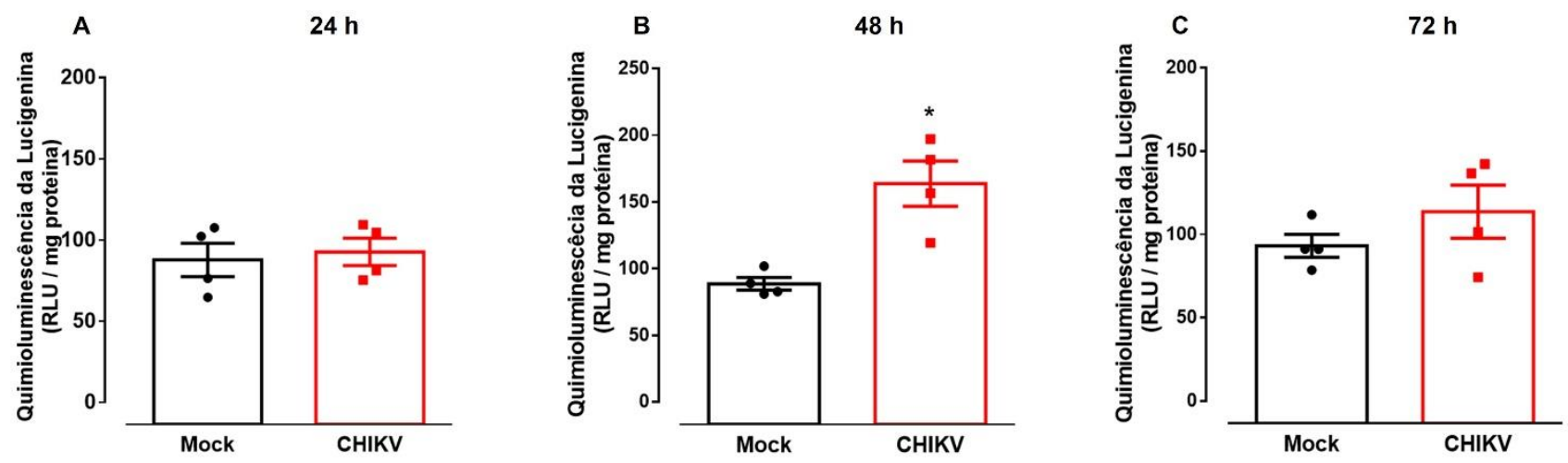

Figura 3. A infecção com CHIKV aumenta a geração de ânion superóxido $\left(\mathrm{O}_{2}{ }^{\bullet-}\right)$ em anéis de aorta. As figuras mostram aumento nas concentrações de ânion superóxido, determinadas pela técnica de quimiluminescência com lucigenina, no tempo de 48 h pós-infecção (B). Os dados representam a média \pm EPM. Teste t de Student: *, p<0,05 vs. Mock; $\mathrm{n}=4$ animais/grupo.

\subsection{AVALIAÇÃO DA GERAÇÃO DE PERÓXIDO DE HIDROGÊNIO $\left(\mathrm{H}_{2} \mathrm{O}_{2}\right)$}

No tempo de 48 h pós-infecção com CHIKV houve diminuição na produção de $\mathrm{H}_{2} \mathrm{O}_{2}$, determinada pela quimiluminescência com Amplex Red (Figura 4B). Não foi detectado alteração de EROs nos tempos de 24 h (Figura 4A) ou 72 h (Figura 4C). 

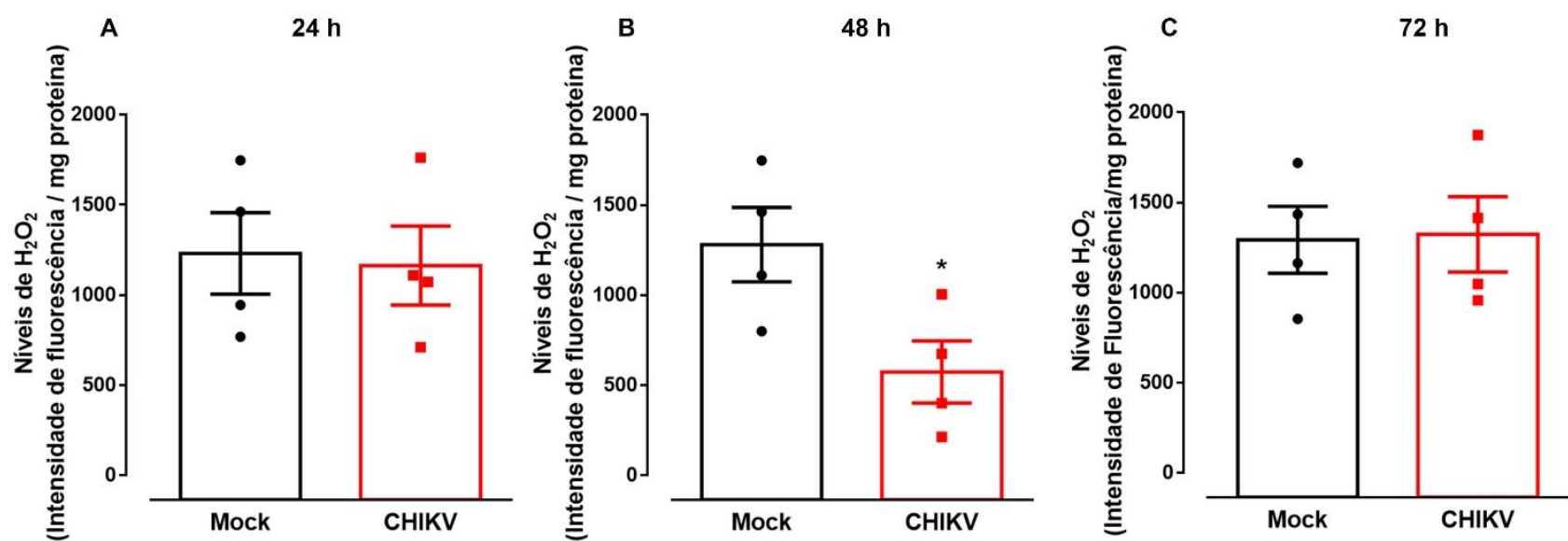

Figura 4. A infecção com CHIKV promove diminuição da geração peróxido de hidrogênio $\left(\mathrm{H}_{2} \mathrm{O}_{2}\right)$ em anéis de aorta. As figuras mostram as concentrações de peróxido de hidrogênio, determinadas pela quimiluminescência com Amplex Red. No tempo de 48 h pós-infecção houve diminuição dos níveis de $\mathrm{H}_{2} \mathrm{O}_{2}$ (B). Os dados representam a média \pm EPM. Teste $t$ de Student: *, p<0,05 vs. Mock; n=4 animais/grupo.

\subsection{AVALIAÇÃO DA PRODUÇÃO DE NITRITO $\left(\mathrm{NO}_{2}{ }^{-}\right)$}

Animais infectados por CHIKV apresentaram concentrações aumentadas de nitrato no soro, 48 h pós-infecção. A produção de NO foi mensurada indiretamente através da concentração de $\mathrm{NO}_{2}^{-}$(nitrito) no soro dos animais WT_Mock e WT_CHIKV. As concentrações de nitratos no soro dos animais foram obtidas pela subtração dos valores de nitrito dos valores de NOx (nitrito + nitrato).

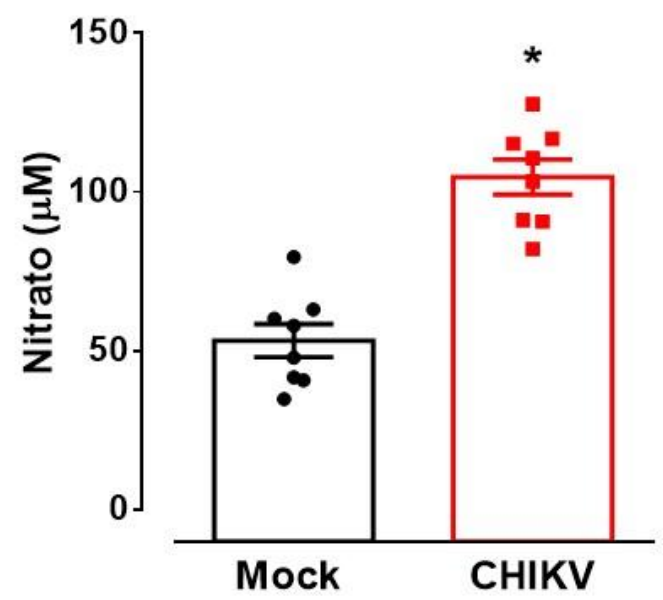

Figura 5. A infecção com CHIKV aumenta os níveis de nitrato. Medida indireta da concentração de NO nos animais infectados por CHIKV (1,0x10 $\left.10^{6} \mathrm{PFU}\right)$ após 48 h. Dados expressos como média \pm E.P.M. * ${ }^{*}$ p $<0,05$ vs. WT_Mock; $\mathrm{n}=8$ animais/grupo. Teste $t$ de Student. WT: Wild type - Camundongos selvagens.

\subsection{AVALIAÇÃO DO PAPEL DO ENDOTÉLIO NA REATIVIDADE VASCULAR EM CAMUNDONGOS INFECTADOS COM CHIKV}

Após análise dos resultados acima descritos, foi padronizado o tempo de $48 \mathrm{~h}$ para avaliações subsequentes de mecanismos no modelo experimental. Neste sentido, realizamos novos ensaios de reatividade vascular em anéis de aorta sem endotélio, no tempo 48 h pósinfecção, para avaliar o papel do endotélio nas alterações vasculares. A remoção do endotélio 
restaurou a resposta vasoconstritora à FEN nos animais infectados 48 h pós-infecção (Figura $6)$.

A

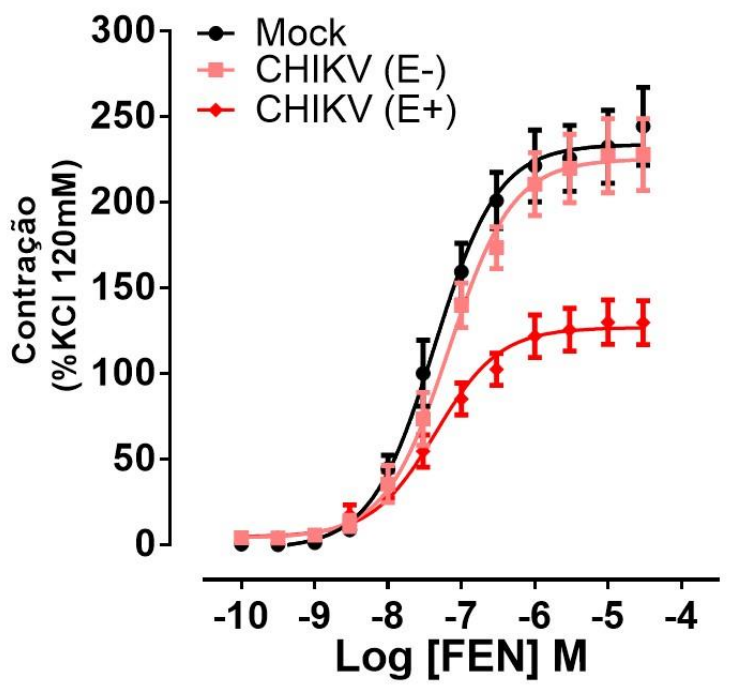

B

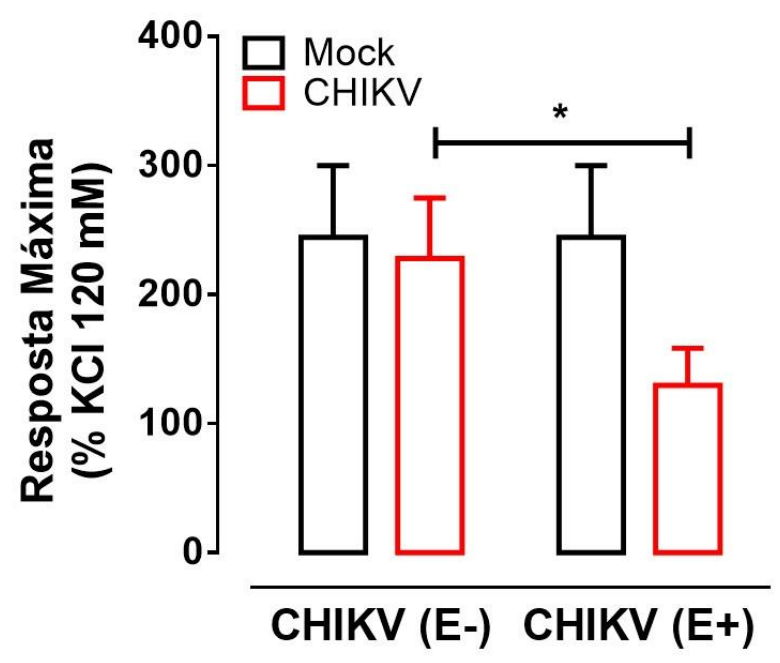

Figura 6. Curvas concentração-efeito cumulativas à fenilefrina (FEN) em anéis de aorta com e sem endotélio. A remoção do endotélio restaurou a resposta vasoconstritora à FEN nos anéis de aorta de animais infectados com CHIKV. Resultados expressos como média \pm EPM. Teste ANOVA de duas vias, seguido de pós- teste de Tukey $\mathrm{n}=5-6$ animais/grupo.

\subsection{CURVAS CONCENTRAÇÃO-EFEITO CUMULATIVAS À FEN NA PRESENÇA DE L-NAME E TIRON}

Visto que a remoção do endotélio restaurou a resposta vasoconstritora à fenilefrina, decidimos avaliar a participação das enzimas óxido nítrico sintase (NOS) e da geração de EROs na alteração de reatividade vascular induzida pela infecção com CHIKV. A incubação com o inibidor não seletivo das NOS, L-NAME $\left(10^{-4} \mathrm{M}\right)$, bem como com Tiron $\left(10^{-5} \mathrm{M}\right.$ - sequestrador seletivo de $\mathrm{O}_{2}{ }^{\circ}$ ), aboliu as diferenças na resposta contrátil a FEN entre anéis de aorta dos animais Mock e infectados com CHIKV (Figura 7). 

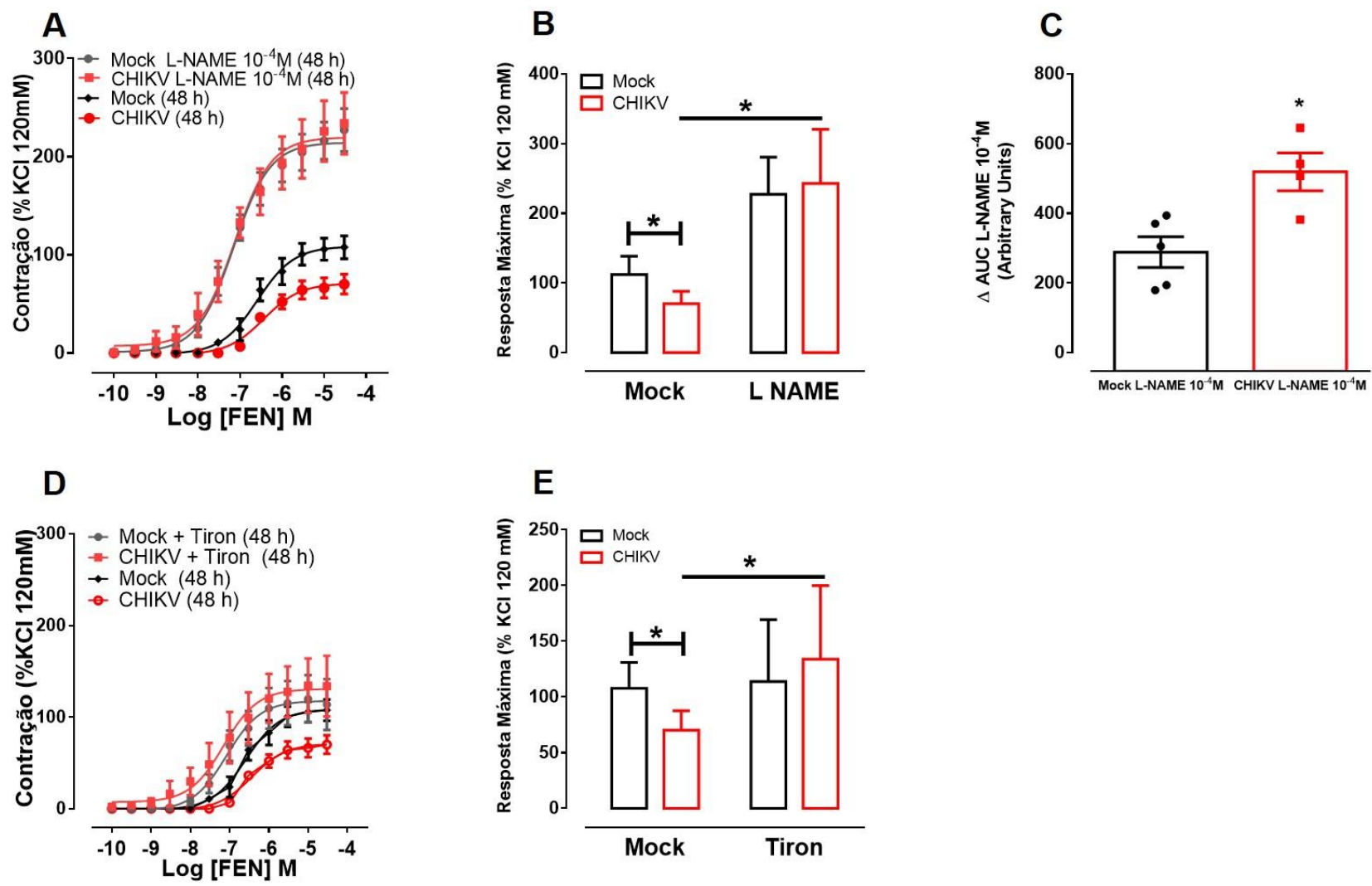

Figura 7. Curvas concentração-efeito cumulativas à FEN na presença de inibidores (Tiron e L- NAME) em aortas torácicas de camundongos C57BL/6J infectados com CHIKV. Curvas concentração-efeito, resposta máxima e delta da área sob a curva ( $\triangle$ AUC) para curvas realizadas na presença do L-NAME $10^{-4} \mathrm{M}(\mathrm{A}, \mathrm{B}$ e $\mathrm{C}$, respectivamente) ou Tiron $10^{-5} \mathrm{M}$ (D e E, respectivamente) e veículo. Dados expressos como média \pm E.P.M. *, $\mathrm{p}<0,05$ vs. Mock. $\mathrm{N}=4-6$ animais em cada grupo experimental. Resposta máxima: Teste $t$ de Student; $\Delta$ AUC LNAME: ANOVA de duas vias.

Tabela 3. Valores de $\mathrm{p} D_{2}$ para FEN na presença de veículo ou inibidores em aortas de camundongos WT Mock e infectados com CHIKV no tempo de 48 h pós-infecção.

\begin{tabular}{lccc}
\hline & Mock & L-NAME & Tiron \\
\hline WT_Mock & $7,12 \pm 0,08$ & $7,15 \pm 0,09$ & $7,07 \pm 0,18$ \\
WT_CHIKV & $7,08 \pm 0,05$ & $7,12 \pm 0,14^{*}$ & $7,15 \pm 0,24^{\#}$ \\
\hline
\end{tabular}

Os dados representam a média \pm S.E.M ( $\mathrm{n}=4-5$ animais/grupo). Teste $t$ de Student: $* \mathrm{p}<0,05$ vs. WT_Mock; ${ }^{\#}$ $\mathrm{p}<0,05$ vs. WT_CHIKV. $\mathrm{p} D_{2}$ : logaritmo negativo da $\mathrm{EC}_{50}$, FEN: fenilefrina, ACh: acetilcolina. WT: Wild type Camundongos selvagens.

\subsection{MEDIDA DA PRESSÃO ARTERIAL EM MODELO EXPERIMENTAL DE INFECÇÃO POR CHIKV}

A pressão arterial foi mensurada antes da infusão dos grupos Mock e CHIKV para obtenção dos valores basais. Observamos que a Pressão Arterial Sistólica (PAS) (Figura 8) foi menor nos animais infectados por CHIKV quando comparada ao grupo controle (Mock). 


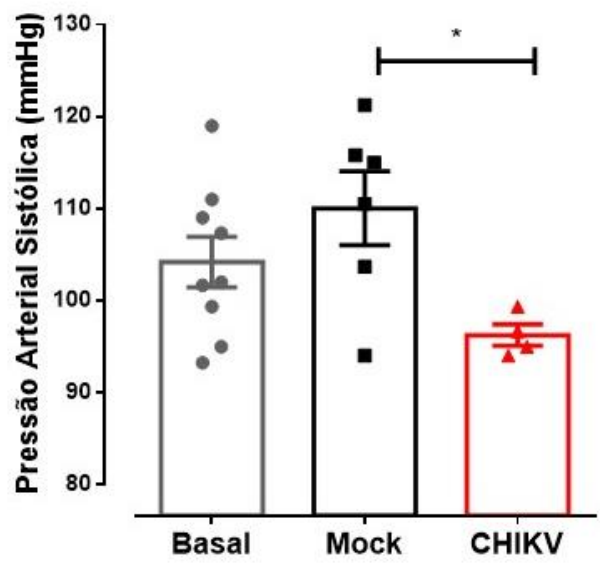

Figura 8. Animais infectados por CHIKV apresentam diminuição da pressão arterial sistólica 48 h pósinfecção. Medida da Pressão Arterial Sistólica $(\mathrm{mmHg})$, antes (basal) e $48 \mathrm{~h}$ após a infusão de veículo ou CHIKV $\left(1,0 \times 10^{6} \mathrm{PFU}\right)$, determinada por pletismografia de cauda. Dados expressos como média \pm E.P.M. ${ }^{*}, \mathrm{p}<0,05$ vs. WT_Mock; n=4-9 animais/grupo. Teste ANOVA de duas vias com pós-teste de Tukey. WT: Wild type Camundongos selvagens.

\subsection{AVALIAÇÃO DOS COMPONENTES DA VIA NF- $\kappa$ B EM MODELO EXPERIMENTAL DE INFECÇÃO POR CHIKV}

Componentes que indicam a ativação da via do NF-kB foram avaliados em aortas do modelo experimental de infecção por CHIKV. Inicialmente, a expressão das formas total e fosforilada da p65 foi avaliada. As aortas dos animais WT_CHIKV apresentam diminuição na expressão proteica da NF-אB p65 total (Figura 9A). Contudo, houve aumento na expressão da proteína (p)-NF-кB p65 ${ }^{\text {Ser536 }}$ (Figura 9B). Sendo assim, analisamos a razão entre a (p)-NF-kB p65 aumento nos animais infectados. Além disso, houve aumento na expressão proteica de iNOS (Figura $8 \mathrm{C})$. 
A
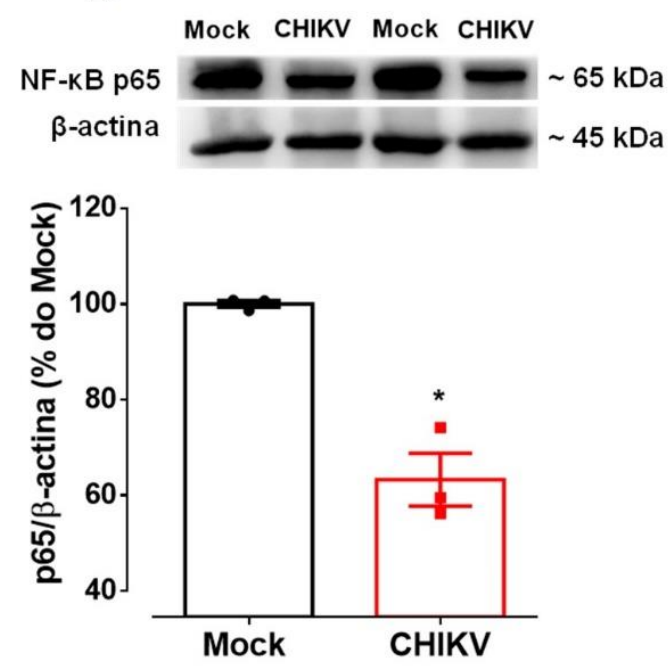

C

Mock CHIKV Mock CHIKV
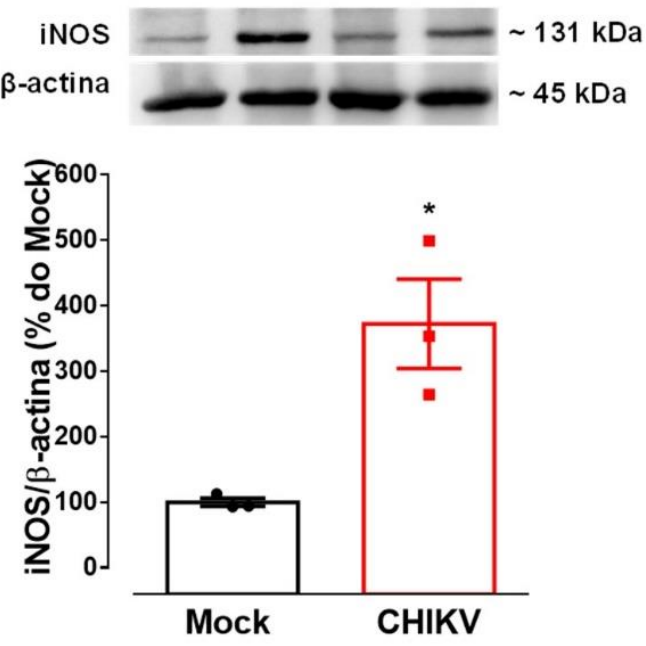

E

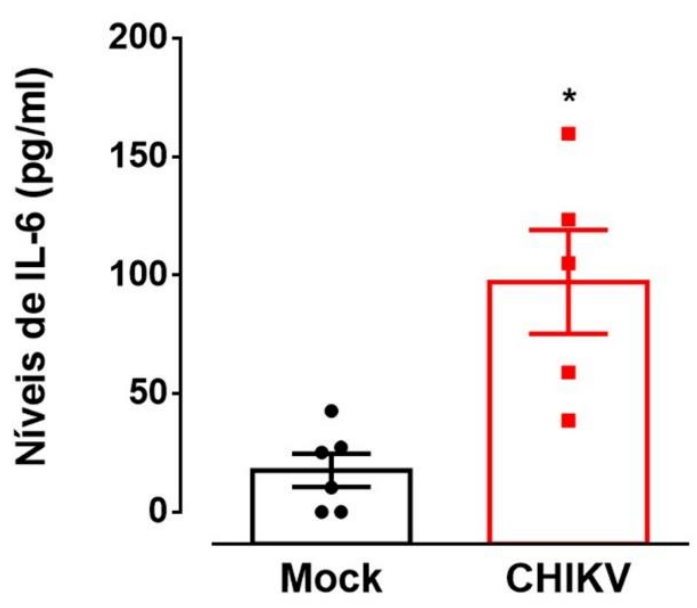

B
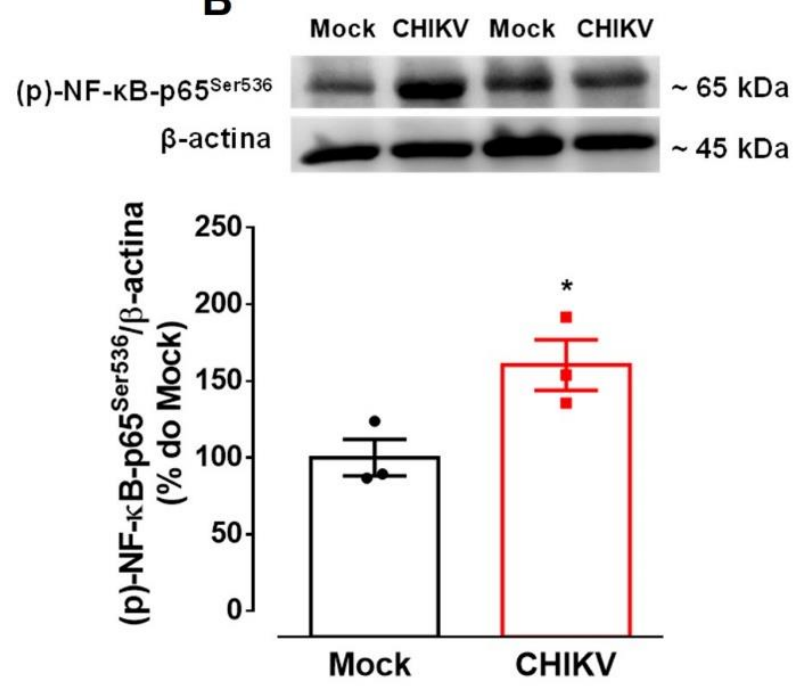

D

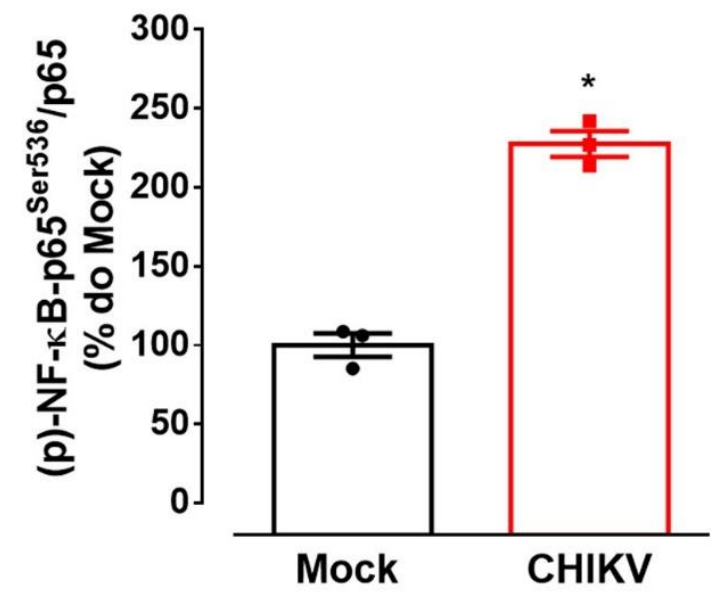

Figura 9. A infecção com CHIKV aumenta a expressão vascular de componentes que indicam ativação da via

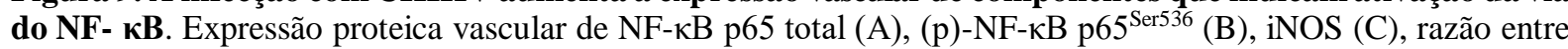

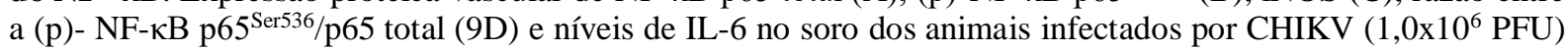
ou veículo, por 48 h. Dados expressos como média \pm E.P.M. *, p<0,05 vs. WT_Mock; n=3-6/grupo. WT: Wild type - Camundongos selvagens. 


\subsection{ENSAIOS IN VITRO}

\subsubsection{Avaliação da geração de ânion superóxido $\left(\mathrm{O}_{2}{ }^{\bullet-}\right)$}

Para avaliar a infecção de células endoteliais por CHIKV, incubamos células endoteliais (EA.hy926) com MOCK ou CHIKV por diferentes tempos (24 h, 48 h, 72 h). Verificamos que no tempo de 48 h e com o MOI de 1,0, CHIKV aumentou a geração de EROs (Figura 10A), bem como aumentou a peroxidação lipídica (Figura 10B).
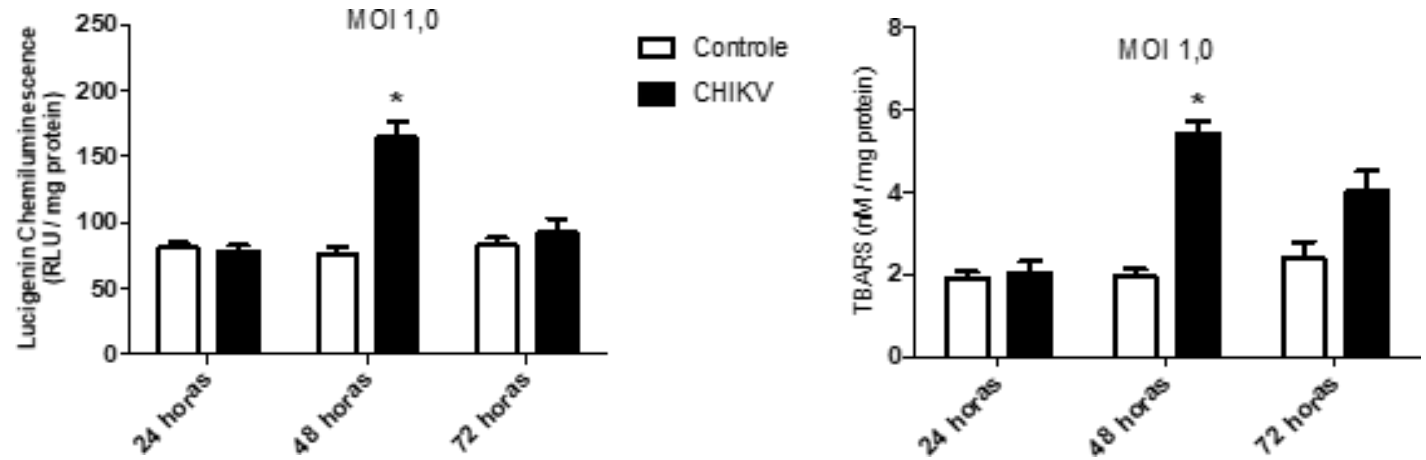

Figura 10. A infecção de células endoteliais com CHIKV aumenta ânion superóxido $\left(\mathrm{O}_{2}^{\bullet}:\right)$ e marcadores de estresse oxidativo. O gráfico mostra medidas de ânion superóxido e os níveis de marcadores de estresse oxidativo, substâncias que reagem com o ácido tiobarbitúrico, após 48 h de infecção e MOI 1,0. Os dados foram obtidos através da técnica de quimiluminescência com lucigenina e ensaio com TBARS. Os dados representam a média \pm EPM. Teste t de Student, *, p<0,05 vs. Mock; n=6/grupo.

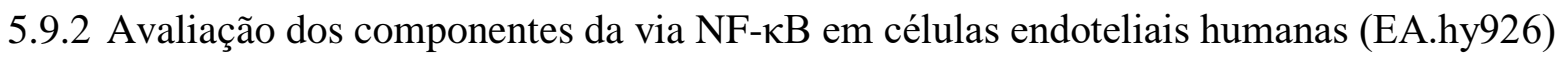

Componentes que indicam a ativação da via do NF-אB, como expressão de ICAM-1, foram avaliados conforme descrito anteriormente. Células endoteliais apresentaram aumento na expressão proteica da molécula de adesão ICAM-1. Os níveis de IL-6 no sobrenadante dessas células também estavam aumentados (Figura 5A).

A

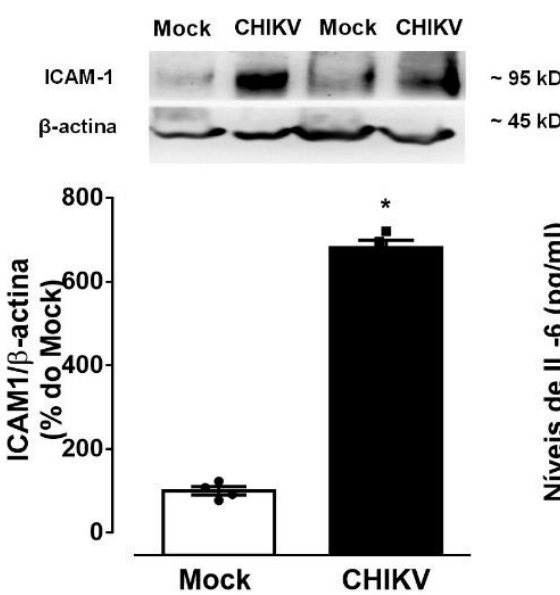

B

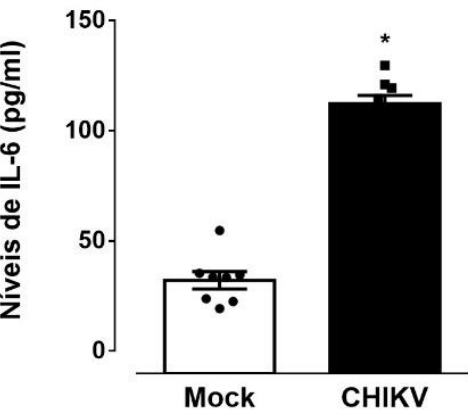


Figura 11. A infecção com CHIKV aumenta componentes que indicam ativação da via do NF- $\kappa B$ em células endoteliais (AE.hy926). Expressão proteica de ICAM-1 (A) e níveis de IL-6 (B) no sobrenadante de células endoteliais infectadas por CHIKV (MOI 1,0) ou veículo, por 48 h. Dados expressos como média \pm E.P.M. *, $\mathrm{p}<0,05$ vs. WT_Mock; $\mathrm{n}=4-8$ experimentos/grupo. Teste $t$ de Student. WT: Wild type - Camundongos selvagens. 
6 DISCUSSÃ̃ 


\section{DISCUSSÃO}

As infecções por arbovírus continuam aumentando a cada ano influenciadas por diversos fatores como a globalização, adaptação dos vírus a novos vetores, entre outros. Isso afeta diretamente milhões de pessoas e gera diversos problemas à saúde pública (AMDEKAR \& PARASHAR \& ALAGARASU, 2017). Assim como ocorre em outras infecções virais, a CHIKV é caracterizada por diversos sinais e sintomas, incluindo alterações cardiovasculares (ALVAREZ et al., 2017). Porém, os mecanismos envolvidos ainda não são bem compreendidos.

Sendo assim, diante da nossa hipótese inicial, que postula que a infecção pelo arbovírus CHIKV promove comprometimento vascular alterando a produção e sinalização do óxido nítrico (NO), se faz necessário compreender melhor o papel do NO na infecção por CHIKV e descrever os mecanismos envolvidos nas alterações vasculares.

Inicialmente, para definição do modelo experimental de infecção por CHIKV, buscamos compreender quais seriam os efeitos da infecção por Chikungunya sob a função vascular. No tempo de 24 h pós-infecção não houve alterações nas respostas vasculares contráteis e relaxantes. A infecção por $48 \mathrm{~h}$ com o CHIKV resultou em acentuada hiporresponsividade contrátil à fenilefrina, porém não houve alteração na resposta vasodilatadora induzida por acetilcolina na aorta dos animais. Estes eventos foram avaliados pela realização de curvas concentração-efeito para fenilefrina, agonista alfa- adrenérgico e, acetilcolina, agonista de receptores muscarínicos que induz vasodilatação dependente do endotélio, respectivamente.

Tais efeitos podem ser decorrentes de provável ativação na via de sinalização do NO em células endoteliais, uma vez que o NO é um importante vasodilatador, mas que, em excesso, pode levar à disfunção vascular e, em casos severos, resultar em vasoplegia, como acontece na sepse (DINERMAN; LOWENSTEIN; SNYDER, 1993; KANDASAMY et al., 2011).

Corroborando esta sugestão, animais infectados por CHIKV apresentam maior concentração de nitrato, indicando maior quantidade de NO circulante. Além disso, nossos dados reforçam a participação do endotélio nesse processo. Curvas concentração-efeito cumulativas à fenilefrina (FEN) foram realizadas em anéis de aorta sem endotélio de animais infectados (CHIKV) ou infundidos com veículo (Mock) e a remoção do endotélio restaurou a resposta contrátil à FEN em aortas de animais infectados. Com isso, sugerimos que o endotélio atua na hiporresponsividade vascular à FEN em animais infectados com CHIKV.

Visto que a remoção do endotélio restaurou a resposta vasoconstritora à fenilefrina e que NO é o principal agente vasodilatador produzido em vasos de condutância, avaliamos a participação de enzimas óxido nítrico sintase (NOS), que são as principais produtoras de NO, e 
da geração de EROs, considerando que estas podem reagir com o NO e reduzir sua biodisponibilidade, nas alterações induzidas pela infecção viral. A incubação com o inibidor não seletivo das NOS, L- NAME $\left(10^{-4} \mathrm{M}\right)$, bem como a incubação com Tiron $\left(10^{-5} \mathrm{M}\right.$ - sequestrador seletivo de $\mathrm{O}_{2}^{\bullet-}$ ), restaurou a resposta contrátil dos anéis de aorta dos animais infectados.

$\mathrm{Na}$ mesma linha dos nossos achados, em modelo experimental de infecção pelo vírus influenza, macrófagos exsudados e células epiteliais brônquicas em tecidos pulmonares de camundongos infectados expressam iNOS e a produção de NO é completamente anulada pela

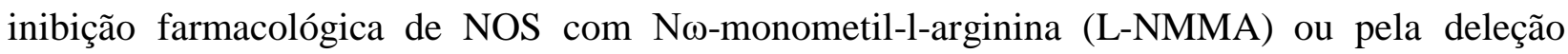
genética da iNOS, indicando que a produção excessiva de NO é decorrente da expressão de iNOS em áreas da infecção viral (AKAIKE et al., 1996). Porém, no nosso modelo, o aumento da iNOS foi observado na aorta dos animais, contribuindo para redução da resposta contrátil e, provavelmente, esse aumento é relacionando a alterações no endotélio, visto que a sua remoção restaurou a resposta vascular.

Peterhans (1979) forneceu a primeira evidência de que uma infecção viral aumenta a produção de EROs. Em nosso estudo, a infecção por CHIKV foi acompanhada por aumento da geração de EROs, o que pode levar a efeitos negativos em células vasculares. As EROs são elementos importantes de defesa de células antimicrobianas (RESHI et al., 2014). A infecção com CHIKV aumentou ânion superóxido $\left(\mathrm{O}_{2}^{--}\right)$em células endoteliais. No sistema vascular, as EROs modulam a função endotelial, tônus e integridade vascular. Entretanto, também podem desempenhar papel fisiopatológico em processos inflamatórios, de hipertrofia proliferação, apoptose, constrição, migração, fibrose e angiogênese, os quais são importantes para a disfunção endotelial, alterações da contração vascular e remodelamento arterial nas doenças cardiovasculares.

Semelhante à geração de EROs nas células endoteliais infectadas, também observamos que a infecção com CHIKV aumentou os níveis de ânion superóxido $\left(\mathrm{O}_{2}{ }^{\bullet}\right)$ nos animais. A modulação do estresse oxidativo em pacientes com Chikungunya que sofrem de poliartralgia persistente é condicionada pela expressão de Siglec-9 (lectina 9 do tipo Ig ligada ao ácido siálico) em monócitos. Além disso, algumas citocinas inflamatórias (IL-6, IFN- $\gamma$, CXCL-9, IL- 10 e TGF $\beta 1$ ) estão significativamente aumentadas nesses pacientes, contribuindo para o ambiente próoxidante (BANERJEE \& MUKHOPADHYAY, 2018). Esse estudo reforça parcialmente a nossa hipótese, visto que a infecção com Chikungunya gerou estresse oxidativo em células endoteliais e em segmentos vasculares (aortas), além de ter aumentado a expressão de marcadores inflamatórios da via do NF-кB. 
A família de fatores de transcrição da proteína de ligação do intensificador do fator nuclear $\kappa(\mathrm{NF}-\kappa \mathrm{B})$ regula a expressão de uma grande variedade de genes envolvidos em diversos

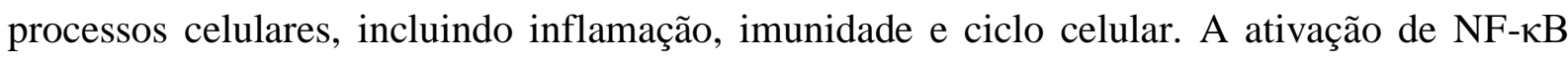
requer ubiquitinação, uma modificação altamente conservada e versátil que pode regular a sinalização celular por mecanismos dependentes e independentes de proteassoma (CHEN \& CHEN, 2013).

O fator nuclear-kappa B (NF-kB) é um fator de transcrição envolvido nos processos inflamatórios e oxidativos (HAYDEN \& GHOSH, 2008). O NF-kB é mantido no citoplasma em uma forma não ativada por associação com uma subunidade inibidora, IkB, em ausência de estímulos inflamatórios. Em resposta a estímulos inflamatórios, a proteólise de I-kB expõe um local de reconhecimento nuclear de NF-kB e favorece sua translocação para o núcleo, aumentando a transcrição de genes para numerosas citocinas, fatores de crescimento e moléculas de adesão (HAYDEN \& GHOSH, 2008).

$\mathrm{O}$ NF-אB aumenta a expressão gênica de citocinas pró-inflamatórias (MILANOVIC; MICHAEL; SCHMITZ, 2014). Nossos resultados demonstram maior expressão de genes relacionados ao / controlados pelo NF- $\kappa \mathrm{B}$, como NF- $\kappa \mathrm{B}$ p65 e iNOS, nas aortas dos animais infectados, bem como maior expressão de ICAM-1 em células endoteliais, além de níveis aumentados de IL-6 em ambos.

Quando a produção celular de EROs supera sua capacidade antioxidante, isso leva a um estado de estresse oxidativo que, por sua vez, contribui para a patogênese de várias doenças humanas. As EROs podem causar toxicidade celular ao reagir com proteínas, lipídios (peroxidação de lipídios) e ácidos nucléicos (danos ao DNA e quebras de fita) (STAAL; ROEDERER; HERZENBERG, 1990).

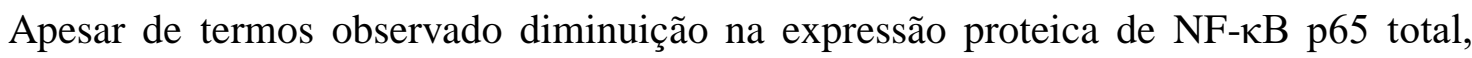

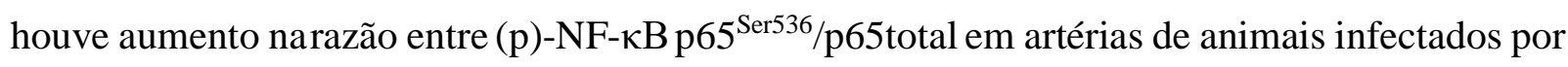
CHIKV. A fosforilação de $\operatorname{Ser}^{536}$ da subunidade p65 contribui para o aumento da eficiência da

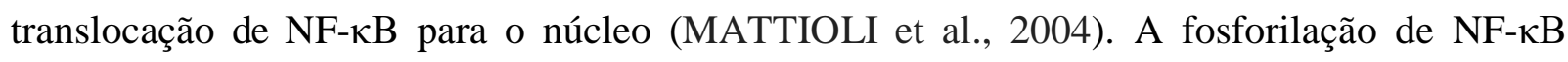
p65 ${ }^{\text {Ser536 }}$ regula a interação com fatores corepressores e coativadores, contribuindo assim diretamente para o aumento da transativação de genes (BUSS et al. 2004), o que poderia justificar o aumento de iNOS e ICAM-1 observado em artérias dos animais infectados.

A fosforilação de $\operatorname{Ser}^{276}$ em RelA mostrou ser dependente de EROs (JAMALUDDIN et

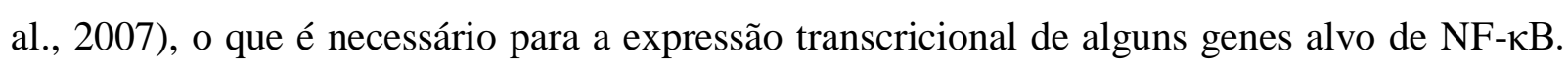
Nesse contexto, a N-acetilcisteína induz fosforilação em Ser ${ }^{536}$ e aumenta a ligação ao DNA por 
meio da ativação da fosfatidilinositol-3 quinase (PI3K) (LIU; YOSHIDA; YAMASHITA, 2008). WU et al. (2009) demonstraram que a exposição ao estresse oxidativo sustentado pode levar à inativação do proteassoma e, consequentemente, inibir a ativação do NF- $\kappa \mathrm{B}$, impedindo

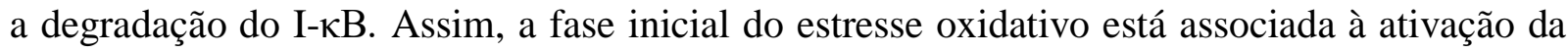
via do NF- $\mathrm{B}$.

Reforçando nossos resultados, outros estudos demonstraram geração de EROs em células endoteliais estimuladas por citocinas durante a infecção por Dengue (MATSUBARA \& ZIFF, 1986; ANDERSON et al., 1997). As EROs podem atacar ácidos graxos poli-insaturados e iniciar a peroxidação lipídica, processo que pode levar à perda da função e integridade da membrana. Além disso, há evidências que o aumento da permeabilidade vascular observada na Dengue Hemorrágica é causado por disfunção celular e não por destruição estrutural das células endoteliais (KURANE \& TAKASAKI, 2001).

Acredita-se que muitos efeitos patológicos do NO sejam produzidos por meio de sua interação com radicais de oxigênio, particularmente $\mathrm{O}_{2} \square-$, produzindo peroxinitrito $\left(\mathrm{ONOO}^{-}\right)$ (REITER; TENG \& BECKMAN, 2000; BECKMAN et al., 1990). Diversos trabalhos têm demonstrado que vírus de DNA e RNA podem induzir a superprodução de EROs, causando danos celulares e morte (LAI et al., 2019; RESHI et al., 2014). Como as EROs estão relacionadas à ativação celular, as mesmas podem facilitar a replicação viral, dependendo da célula e do vírus (CAMINI et al., 2017). No nosso trabalho, observamos que aumento de ROS nas células endoteliais foi acompanhado pelo aumento de lipídios peroxidados, avaliados pelo TBARS.

Contudo, algumas etapas são necessárias para completar o presente estudo. Neste sentido, pretendemos caracterizar possíveis alterações na massa corporal e na temperatura dos animais após a infecção por CHIKV, além de avaliar marcadores pro e anti-inflamatórios (INF$\gamma$, TNF- $\alpha$, IL-10), característicos de infecções virais. Também pretendemos confirmar a participação da iNOS nas alterações vasculares dos animais infectados por CHIKV.

Para isto avaliaremos a resposta vascular a FEN na presença do inibidor seletivo da iNOS (1400W) ou utilizando animais knockouts (iNOS \%) e realizando curvas a FEN em artérias com e sem endotélio; também avaliaremos os níveis de peroxidação lipídica nas aortas dos animais Mock e CHIKV. Além disso, pretendemos avaliar a participação do complexo enzimático NADPH oxidase na geração de EROs, visto que as NADPH oxidases representam família de enzimas pró-oxidantes especializada na produção de EROs e que pode ser ativada por agentes pró-inflamatórios. Também serão realizados novos ensaios in vitro com células 
endoteliais (EA.hy926), na presença do inibidor Pirrolidina Ditiocarbamato (PDTC), para explorar a influência do NF- $\mathrm{BB}$ como mediador das repostas inflamatórias e funcionais observadas. 


\section{CONCLUSÃO}

Os resultados apresentados neste estudo fornecem evidências que a infecção por CHIKV induz produção vascular de EROs e aumento de NO e aumento da expressão de iNOS, alterando a sinalização do NO e ativando processos inflamatórios em células endoteliais, com consequente disfunção vascular. Estes efeitos são decorrentes de ações diretas do CHIKV em células vasculares e podem contribuir para as alterações cardiovasculares na patogênese da Chikungunya. 
REFERÊNCIAS 


\section{REFERÊNCIAS}

AIRD, W. C. Endothelium in health and disease. Pharmacological reports, v. 60, n. 1, p. $139,2008$.

AIRD, W. C. Phenotypic heterogeneity of the endothelium: I. Structure, function, and mechanisms. Circulation research, v. 100, n. 2, p. 158-173, 2007.

AKAIKE, T.; MAEDA, H. Nitric oxide and virus infection. Immunology, v. 101, n. 3, p. 300-308, 2000.

AKAIKE, T.; MAEDA, H. Nitric oxide in influenza. Nitric Oxide and infection. Springer, Boston, MA, p. 397-415, 2002.

AKAIKE, T. et al. Pathogenesis of influenza virus-induced pneumonia: involvement of both nitric oxide and oxygen radicals. Proceedings of the National Academy of Sciences, v. 93, n. 6, p. 2448-2453, 1996.

AKAIKE, T.; SUGA, M.; MAEDA, H. Free radicals in viral pathogenesis: molecular mechanisms involving superoxide and NO. Proceedings of the Society for Experimental Biology and Medicine, v. 217, n. 1, p. 64-73, 1998.

ALMEIDA, L. T. et al. Zika virus induces oxidative stress and decreases antioxidant enzyme activities in vitro and in vivo. Virus Research, v. 286, p. 198084, 2020.

ALVAREZ, M. F. et al. Cardiovascular involvement and manifestations of systemic Chikungunya virus infection: A systematic review. F1000Research, v. 6, 2017.

AMDEKAR, S.; PARASHAR, D.; ALAGARASU, K.. Chikungunya virus-induced arthritis: role of host and viral factors in the pathogenesis. Viral immunology, v. 30, n. 10, p. 691-702, 2017.

ANDERSON, R. et al. Activation of endothelial cells via antibody-enhanced dengue virus infection of peripheral blood monocytes. Journal of virology, v. 71, n. 6, p. 4226-4232, 1997.

BANERJEE, N.; MUKHOPADHYAY, S. Oxidative damage markers and inflammatory cytokines are altered in patients suffering with post-chikungunya persisting polyarthralgia. Free radical research, v. 52, n. 8, p. 887-895, 2018.

BECKMAN, J. S. et al. Apparent hydroxyl radical production by peroxynitrite: implications for endothelial injury from nitric oxide and superoxide. Proceedings of the National Academy of Sciences, v. 87, n. 4, p. 1620-1624, 1990.

BOGDAN, C. et al. Mechanism of suppression of nitric oxide synthase expression by interleukin-4 in primary mouse macrophages. Journal of Leukocyte Biology, v. 55, n. 2, p. 227-233, 1994.

BROWN, C. M.; BIDLE, K. D. Attenuation of virus production at high multiplicities of infection in Aureococcus anophagefferens. Virology, v. 466, p. 71-81, 2014. 
BURT, F. J. et al. Chikungunya virus: an update on the biology and pathogenesis of this emerging pathogen. The Lancet Infectious Diseases, v. 17, n. 4, p. e107-e117, 2017.

BUSS, H. et al. Constitutive and interleukin-1-inducible phosphorylation of p65 NF- $\mathrm{kB}$ at serine 536 is mediated by multiple protein kinases including I $\mathrm{B}$ kinase (IKK)- $\alpha$, IKK $\beta$, IKK $\epsilon$, TRAF family member-associated (TANK)-binding kinase 1 (TBK1), and an unknown kinase and couples p65 to TATA-binding protein-associated factor II31-mediated interleukin8 transcription. Journal of Biological Chemistry, v. 279, n. 53, p. 55633-55643, 2004.

CHEN, J.; CHEN, Z. J. Regulation of NF- $\kappa B$ by ubiquitination. Current opinion in immunology, v. 25, n. 1, p. 4-12, 2013.

CORRALIZA, I. M. et al. Arginase induction by suppressors of nitric oxide synthesis (IL-4, IL-10 and PGE2) in murine bone-marrow-derived macrophages. Biochemical and biophysical research communications, v. 206, n. 2, p. 667-673, 1995.

CUNHA, F. Q.; MOHCADA, S.; LIEW, F. Y. Interleukin-10 (IL-10) inhibits the induction of nitric oxide synthase by interferon- $\gamma$ in murine macrophages. Biochemical and biophysical research communications, v. 182, n. 3, p. 1155-1159, 1992.

DURBIN, A. P. et al. Phenotyping of peripheral blood mononuclear cells during acute dengue illness demonstrates infection and increased activation of monocytes in severe cases compared to classic dengue fever. Virology, v. 376, n. 2, p. 429-435, 2008.

ELONG NGONO, A.; SHRESTA, S. Immune response to dengue and Zika. Annual review of immunology, v. 36, p. 279-308, 2018.

FÉLÉTOU, M.; HUANG, Y.; VANHOUTTE, P. M. Endothelium-mediated control of vascular tone: COX-1 and COX-2 products. British journal of pharmacology, v. 164, n. 3, p. 894-912, 2011.

FÖRSTERMANN, U.; SESSA, W. C. Nitric oxide synthases: regulation and function. European heart journal, v. 33, n. 7, p. 829-837, 2012.

FUJII, S.; AKAIKE, T.; MAEDA, H. Role of nitric oxide in pathogenesis of herpes simplex virus encephalitis in rats. Virology, v. 256, n. 2, p. 203-212, 1999.

FULLERTON, J. N.; GILROY, D. W. Resolution of inflammation: a new therapeutic frontier. Nature reviews Drug discovery, v. 15, n. 8, p. 551, 2016.

GANDINI, M. et al. Dengue-2 and yellow fever 17DD viruses infect human dendritic cells, resulting in an induction of activation markers, cytokines and chemokines and secretion of different TNF- $\alpha$ and IFN- $\alpha$ profiles. Memórias do Instituto Oswaldo Cruz, v. 106, n. 5, p. 594-605, 2011.

GRANGER, D. L. et al. Specific amino acid (L-arginine) requirement for the microbiostatic activity of murine macrophages. The Journal of clinical investigation, v. 81, n. 4, p. 11291136, 1988.

GUZMÁN, M. G.; KOURI, G. Dengue diagnosis, advances and challenges. International 
journal of infectious diseases, v. 8, n. 2, p. 69-80, 2004.

HARRISON, D. G. The mosaic theory revisited: common molecular mechanisms coordinating diverse organ and cellular events in hypertension. Journal of the American Society of Hypertension, v. 7, n. 1, p. 68-74, 2013.

HARVEY, A.; MONTEZANO, A. C.; TOUYZ, R. M. Vascular biology of ageingImplications in hypertension. Journal of molecular and cellular cardiology, v. 83, p. 112$121,2015$.

HAYDEN, M. S.; GHOSH, S. Shared principles in NF-кB signaling. Cell, v. 132, n. 3, p. 344-362, 2008.

HUSSAIN, A. et al. A comprehensive review of the manifestations and pathogenesis of Zika virus in neonates and adults. Cureus, v. 10, n. 9, 2018.

KANDASAMY, K. et al. Atorvastatin prevents vascular hyporeactivity to norepinephrine in sepsis: role of nitric oxide and $\alpha 1$-adrenoceptor mRNA expression. Shock, v. 36, n. 1, p. 76$82,2011$.

KARUPIAH, G. et al. Rapid interferon $\gamma$-dependent clearance of influenza A virus and protection from consolidating pneumonitis in nitric oxide synthase $2-$ deficient mice. The Journal of experimental medicine, v. 188, n. 8, p. 1541-1546, 1998.

KHAN, B. V. et al. Nitric oxide regulates vascular cell adhesion molecule 1 gene expression and redox-sensitive transcriptional events in human vascular endothelial cells. Proceedings of the National Academy of Sciences, v. 93, n. 17, p. 9114-9119, 1996.

KOPROWSKI, H. et al. In vivo expression of inducible nitric oxide synthase in experimentally induced neurologic diseases. Proceedings of the National Academy of Sciences, v. 90, n. 7, p. 3024-3027, 1993.

KOU, Z. et al. Monocytes, but not T or B cells, are the principal target cells for dengue virus (DV) infection among human peripheral blood mononuclear cells. Journal of medical virology, v. 80, n. 1, p. 134-146, 2008.

KRITTANAWONG, C.; ZHANG, H. J.; SUN, T. Cardiovascular complications after Zika virus infection. International journal of cardiology, v. 221, p. 859, 2016.

KUCHARSKI, A.; RILEY, S.. Reducing uncertainty about flavivirus infections. The Lancet Infectious Diseases, v. 17, n. 1, p. 13-15, 2017.

LEDUR, P. F. et al. Zika virus infection leads to mitochondrial failure, oxidative stress and DNA damage in human iPSC-derived astrocytes. Scientific reports, v. 10, n. 1, p. 1-14, 2020.

LIDDIARD, K. et al. Macrophage heterogeneity and acute inflammation. European journal of immunology, v. 41, n. 9, p. 2503-2508, 2011.

LIU, J.; YOSHIDA, Y.; YAMASHITA, U. DNA-binding activity of NF-кB and phosphorylation of $\mathrm{p} 65$ are induced by $\mathrm{N}$-acetylcysteine through phosphatidylinositol (PI) 3- 
kinase. Molecular immunology, v. 45, n. 15, p. 3984-3989, 2008.

LU, W. et al. Piperlongumine Inhibits Zika Virus Replication In vitro and Promotes UpRegulation of HO-1 Expression, Suggesting An Implication of Oxidative Stress. Virologica Sinica, p. 1-11, 2020.

MACLEAN, A. et al. Mice lacking inducible nitric-oxide synthase are more susceptible to herpes simplex virus infection despite enhanced Th1 cell responses. Journal of General Virology, v. 79, n. 4, p. 825-830, 1998.

MATEEN, S. et al. Increased reactive oxygen species formation and oxidative stress in rheumatoid arthritis. PloS one, v. 11, n. 4, p. e0152925, 2016.

MATSUBARA, T.; ZIFF, M. Increased superoxide anion release from human endothelial cells in response to cytokines. The Journal of Immunology, v. 137, n. 10, p. 3295-3298, 1986.

MATTIOLI, I. et al. Transient and selective NF- $\kappa \mathrm{B}$ p65 serine 536 phosphorylation induced by $\mathrm{T}$ cell costimulation is mediated by $\mathrm{I} \kappa \mathrm{B}$ kinase $\beta$ and controls the kinetics of $\mathrm{p} 65$ nuclear import. The Journal of Immunology, v. 172, n. 10, p. 6336-6344, 2004.

MAYER, S. V.; TESH, R. B.; VASILAKIS, N. The emergence of arthropod-borne viral diseases: A global prospective on dengue, chikungunya and zika fevers. Acta tropica, v. 166, p. 155-163, 2017.

MILANOVIC, M.; KRACHT, M.; SCHMITZ, M. Lienhard. The cytokine-induced conformational switch of nuclear factor $\mathrm{\kappa B}$ p65 is mediated by $\mathrm{p} 65$

phosphorylation. Biochemical Journal, v. 457, n. 3, p. 401-413, 2014.

MONCADA, S.; HIGGS, A. The L-arginine-nitric oxide pathway. New England Journal of Medicine, v. 329, n. 27, p. 2002-2012, 1993.

MONTEZANO, A. C.; TOUYZ, R. M. Reactive oxygen species and endothelial function-role of nitric oxide synthase uncoupling and Nox family nicotinamide adenine dinucleotide phosphate oxidases. Basic \& clinical pharmacology \& toxicology, v. 110, n. 1, p. 87-94, 2012.

MUSSO, D.; BAUD, D.; GUBLER, D. J. Zika virus: what do we know?. Clinical Microbiology And Infection, v. 22, n. 6, p.494-496, jun. 2016.

NAGARATNAM, N.; SIRIPALA, K.; DE SILVA, N. Arbovirus (dengue type) as a cause of acute myocarditis and pericarditis. British Heart Journal, v. 35, n. 2, p. 204, 1973.

NATHAN, C. et al. Inducible nitric oxide synthase: what difference does it make?. The Journal of clinical investigation, v. 100, n. 10, p. 2417-2423, 1997.

OLIVEIRA, G. M. M.; FERREIRA, R. M. Yellow fever and cardiovascular disease: an intersection of epidemics. Arquivos Brasileiros de Cardiologia, v. 110, n. 3, p. 207-210, 2018. 
World Health Organization (WHO). A global brief on Hypertension - Silent killer, global public health crisis, 2021.

PACHER, P.; BECKMAN, J. S.; LIAUDET, L. Nitric oxide and peroxynitrite in health and disease. Physiological reviews, v. 87, n. 1, p. 315-424, 2007.

PANTOPOULOS, K.; HENTZE, M. W. Nitric oxide signaling to iron-regulatory protein: direct control of ferritin mRNA translation and transferrin receptor mRNA stability in transfected fibroblasts. Proceedings of the National Academy of Sciences, v. 92, n. 5, p. 1267-1271, 1995.

PEYREFITTE, C. N. et al. Dengue virus infection of human microvascular endothelial cells from different vascular beds promotes both common and specific functional changes. Journal of Medical Virology, v. 78, n. 2, p. 229-242, 2006.

REITER, C. D.; TENG, R. J.; BECKMAN, J. S. Superoxide reacts with nitric oxide to nitrate tyrosine at physiological $\mathrm{pH}$ via peroxynitrite. Journal of Biological Chemistry, v. 275, n. 42, p. 32460-32466, 2000.

RESHI, M. L.; SU, Y. C.; HONG, J. R. RNA viruses: ROS-mediated cell death. International journal of cell biology, v. 2014, 2014.

SONOKI, T. et al. Coinduction of nitric-oxide synthase and arginase I in cultured rat peritoneal macrophages and rat tissues in vivo by lipopolysaccharide. Journal of Biological Chemistry, v. 272, n. 6, p. 3689-3693, 1997.

SOUNDRAVALLY, R. et al. Oxidative stress in severe dengue viral infection: association of thrombocytopenia with lipid peroxidation. Platelets, v. 19, n. 6, p. 447-454, 2008.

STANLEY, C. P. et al. Singlet molecular oxygen regulates vascular tone and blood pressure in inflammation. Nature, v. 566, n. 7745, p. 548-552, 2019.

STAPLES, J. E.; FISCHER, M. Chikungunya virus in the Americas-what a vectorborne pathogen can do. New England Journal of Medicine, v. 371, n. 10, p. 887-889, 2014.

STUEHR, D. J.; GRIFFITH, O. W. Mammalian nitric oxide synthases. Advances in enzymology and related subjects, v. 65, p. 287-346, 1992.

THIRUVENGADAM, K. V.; KALYANASUNDARAM, V.; RAJGOPAL, J. Clinical and pathological studies on chikungunya fever in Madras city. The Indian Journal of Medical Research, v. 53, n. 8, p. 729-744, 1965.

TSUTSUMI, H. et al. Respiratory syncytial virus infection of human respiratory epithelial cells enhances inducible nitric oxide synthase gene expression. Journal of leukocyte biology, v. 66, n. 1, p. 99-104, 1999.

UMEZAWA, K. et al. Induction of nitric oxide synthesis and xanthine oxidase and their roles in the antimicrobial mechanism against Salmonella typhimurium infection in mice. Infection and immunity, v. 65, n. 7, p. 2932-2940, 1997. 
VERVAEKE, P.; VERMEIRE, K.; LIEKENS, S. Endothelial dysfunction in dengue virus pathology. Reviews in medical virology, v. 25, n. 1, p. 50-67, 2015.

WU, M. et al. Sustained oxidative stress inhibits NF- $\mathrm{B}$ activation partially via inactivating the proteasome. Free Radical Biology and Medicine, v. 46, n. 1, p. 62-69, 2009.

ZHANG, Z.; RONG, L.; LI, Y. P. Flaviviridae viruses and oxidative stress: implications for viral pathogenesis. Oxidative medicine and cellular longevity, v. 2019, 2019. 
ANEXOS 

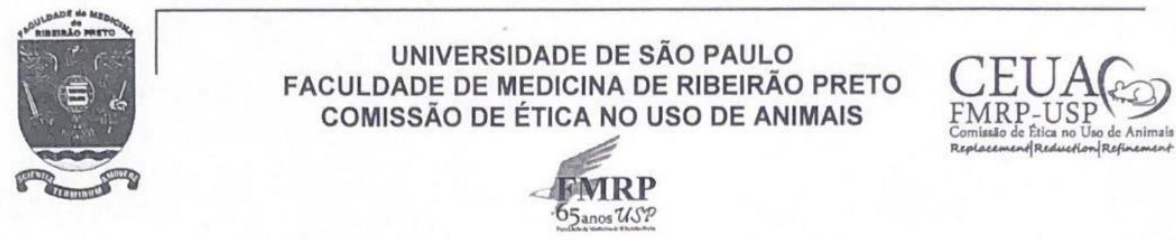

\section{AUTORIZAÇÃ}

A CEUA-FMRP autoriza a execução do projeto intitulado: "Estudo dos efeitos vasculares da infeç̧ão induzida pelo arbovírus chikungunya", registrado com o número do protocolo 171/2019, sob a responsabilidade da Profa. Dra. Rita de Cassia Aleixo Tostes Passaglia, envolvendo a produção, manutenção ou utilização de animais pertencentes ao filo Chordata, subfilo Vertebrata (exceto humanos) para fins de pesquisa científica (ou ensino), encontra-se de acordo com os preceitos da Lei $n^{\circ} 11.794$ de 8 de outubro de 2008, do Decreto ${ }^{\circ} 6.899$ de 15 de julho de 2009 e com as normas editadas pelo Conselho Nacional de Controle de Experimentação Animal (CONCEA). O Protocolo foi APROVADO pela Comissão de Ética no Uso de Animais da Faculdade de Medicina de Ribeirão Preto da Universidade de São Paulo, em reunião de 27 de janeiro de 2020.

$$
\begin{aligned}
& \text { Colaboradores: José Teles de Oliveira Neto } \\
& \text { Emiliana Pereira Abrão da Costa }
\end{aligned}
$$

Lembramos da obrigatoriedade do Relatório Final, em modelo da CEUA, para emissão do Certificado, como disposto nas Resoluções Normativas do CONCEA.

\begin{tabular}{|c|c|c|c|c|}
\hline \multicolumn{3}{|c|}{ Finalidade } & \multicolumn{3}{c|}{ O Ensino $(\mathrm{X})$ Pesquisa Cientifica } \\
\hline \multirow{3}{|c|}{ Vigência da autorizaç̃̃o } & \multicolumn{3}{c|}{$27 / 01 / 2020$ a 01/06/2022 } \\
\hline Espécie/Linhagem & $\begin{array}{c}\mathrm{N}^{\circ} \text { de } \\
\text { Animais }\end{array}$ & Peso/dade & Sexo & Origem \\
\hline Camundongo/C57Bl 6 & 198 & $25 \mathrm{~g} / 42$ dias & Macho & Serviço de Biotério \\
\hline
\end{tabular}

